TI 2001- 113/2

Tinbergen Institute Discussion Paper

\title{
Time- Varying Market Integration and Expected Returns in Emerging Markets
}

Frank de Jong ${ }^{1}$

Frans A. de Roon²

1 Finance Group, Faculty of Economics and Econometrics, University of Amsterdam, CEPR, and Tinbergen Institute,

2 Department of Finance and CentER, Tilburg University, CEPR 
Tinbergen Institute

The Tinbergen Institute is the institute for economic research of the Erasmus Universiteit Rotterdam, Universiteit van Amsterdam and

Vrije Universiteit Amsterdam.

Tinbergen I nstitute Amsterdam

Keizersgracht 482

1017 EG Amsterdam

The Netherlands

Tel.: +31.(0)20.5513500

Fax: $\quad+31 .(0) 20.5513555$

Tinbergen Institute Rotterdam

Burg. Oudlaan 50

3062 PA Rotterdam

The Netherlands

Tel.: $\quad+31 .(0) 10.4088900$

Fax: $\quad+31 .(0) 10.4089031$

Most TI discussion papers can be downloaded at

http://www.tinbergen.nl 


\title{
Time-Varying Market Integration and Expected Returns in Emerging Markets
}

\author{
Frank de J ong and Frans A. de Roon ${ }^{\text {yz }}$ \\ October 9, 2001
}

\footnotetext{
F inance Group, University of A msterdam, Roetersstraat 11, 1018 W B A msterdam, The Netherlands, and CEPR. E-mail: F deJ ong@fee.uva.nl

${ }^{y}$ Department of Finance and CentER, Tilburg University, and CEPR. P.O.B ox 90153, 5000 LE Tilburg, The Netherlands. E-mail: F.A.deR oon@kub.nl

${ }^{z}$ We want to thank Stijn Claessens, Campbell Harvey, Hans Dewachter, J esper R angvid, participants of the 2001 PAI conference on Financial Econometrics in Leuven and the 2001 EFA M eetings in Barcelona, and seminar participants at Tilburg University and the University of $\mathrm{G}$ ent, for providing valuable comments.
} 


\title{
Time-Varying Market Integration and Expected Returns in Emerging Markets
}

\begin{abstract}
A bstract
We use a simple model in which the expected returns in emerging markets depend on their systematic risk as measured by their beta relative to the world portfolio as well as on the level of integration in that market. The level of integration is a time-varying variable that depends on the market value of the assets that can be held by domestic investors only versus the market value of the assets that can be traded freely. Our empirical analysis for 30 emerging markets shows that there are strong exects of the level of integration or segmentation on the expected returns in emerging markets. The expected returns depend both on the level of segmentation of the emerging market itself and on the regional segmentation level. We also ..nd that there is signi...cant time-variation in the betas relative to the world portfolio because of the level of segmentation. For the composite index of the emerging markets we ..nd an annual increase in beta of 0.09 due to decreased segmentation of the emerging markets in our sample period. In terms of expected returns the total exect on the composite index translates into an average decrease of 4.5 percent per annum. As predicted by our model, the noninvestable assets are more sensitive to the local and less to the regional level of segmentation than the investable assets. These conclusions do not change when using additional control variables. We do not ..nd a clear pattern between volatility and segmentation, however.
\end{abstract}




\section{Introduction}

An important issue in international ..nancial markets is the exect of market segmentation on expected returns. A sset pricing models such as the International CAPM assume that markets are completely integrated, implying that expected returns depend on the covariance with the return on the world market portfolio and possibly with currency deposit returns. (see, e.g., Adler and Dumas (1983)). If markets are (partially) segmented, then the International CAPM no longer applies, and other factors enter the pricing relation as well (see, e.g., Errunza and Losq (1985)).

It is generally believed that as markets become more integrated, the cost of capital decreases because the removal of investment barriers allows for risk sharing between domestic and foreign agents (see, e.g., Stulz (1999)). In a recent paper, Bekaert and Harvey (2000) study the exect of capital market liberalizations, i.e., a country's decision to open up the equity market, allowing the market to become more integrated with the rest of the world. Bekaert and Harvey ..nd that the cost of capital decreases by 5 to 75 basis points after a capital market liberalization. Similarly, Henry (2000) analyzes the announcement exects of emerging market liberalizations, and ..nds that a country's equity price index shows an abnormal return of 3.3 percent per month during an eight-month period, implying a total price increase of about 25 percent. B ased on stock returns for 126 ..rms in 32 countries, Errunza and Miller (2000) report a reduction in the cost of capital of 11.3 percentage points following ADR introductions. Thus, there appears to be strong evidence that market liberalizations lead to lower expected returns in emerging markets.

Bekaert and Harvey (1995) and Stulz (1999) stress the fact that the degree to which markets are integrated or segmented is not ..xed, but changes gradually over time and that liberalizations are not one-shot events. To the extent that expected returns depend on the level of integration, time variation in the degree of integration implies that expected returns are time-varying as well. Bekaert and Harvey (1995) estimate the degree of integration for 21 developed markets and 12 emerging markets and show that indeed markets become either more or less integrated over time. Carrieri, Errunza, and Hogan (2001) document the time-variation in the level of integration for seven emerging markets. They ..nd that there is a lot of cross-sectional variation in the level of integration and a strong increase in integration over time.

The aim of this paper is to account for time variation in market integration when assessing the exects of market integration on expected returns 
in emerging markets. We use a simple model similar in spirit to the model of Errunza and Losq (1985) in which expected returns depend on the level of market segmentation, as measured by the fraction of assets in a market that cannot be traded by foreign investors. ${ }^{1}$ Since the level of segmentation changes over time, expected returns should be time-varying as well. For a set of 30 emerging markets, we show the exect of market segmentation on expected returns to be signi..cant. In addition, our simple model implies that trading restrictions in one market can axect the expected returns in other markets if the correlation between these markets is suф ciently high. Our empirical results show that within a geographic region there are cross exects from trading restrictions in one country on the expected returns in other countries. $^{2}$

These results hold for the freely tradable, or investable, assets. In addition we ..nd that the nontraded, or noninvestable, assets in a country are also axected by the level of segmentation. As predicted by the model, in comparison with the investable indices, the the non-investable returns are more sensitive to the local level of segmentation than to the regional level of segmentation.

As markets open up and become more integrated with the rest of the world, one may expect that the beta of a country relative to the world portfolio increases. Allowing for time-varying betas that are linear in the segmentation variables, we ..nd even stronger segmentation exects on expected returns. The direct exect of segmentation on expected returns and the effect on beta usually have the opposite sign: whereas the direct exect of a decrease in segmentation leads to lower expected returns, it is accompanied by an increase in beta, implying higher expected returns.

For the composite index of all the emerging markets in our dataset the annual increase in beta due to the increases in market integration during our sample period is about 0.09 , which is similar in magnitude to the change in

\footnotetext{
${ }^{1}$ Our model is also similar to the well known CAPM with nontradable assets as in Mayers (1976) and to the hedging pressure models that are used to explain expected returns in futures markets, as proposed by Hirshleifer (1988), and DeRoon, Nijman, and Veld (2000) for instance. The fraction of assets in an economy that cannot be traded by foreign investors, which we use as our segmentation variable, has to be held by domestic investors only, thereby causing an additional premium in tradable assets similar to hedging pressure exects in futures markets.

${ }^{2}$ These cross exects from the regional level of segmentation can even be stronger than the direct exects from the trading restrictions in the country itself.
} 
beta reported by B ekaert and Harvey (2001). In terms of expected returns the total exect on the composite index translates into an annual decrease of 4.5 percent per annum. Our conclusions do not change very much when we control for a country's risk rating and its openness as measured by its imports and exports over GDP. As in previous studies we ..nd that these latter two variables contain information about expected returns in emerging markets, but including them in the regression does not have a big exect on the relevance of the segmentation variable.

Finally, although we ..nd that a decrease in the level of segmentation leads to lower expected returns or costs of capital, we do not ..nd such clear exects for the volatility of the emerging markets returns. We use a GARCH speci..cation for the idisyncratic variance of a market to analyze the exect of segmentation on volatility. Although in many markets the volalitility is signi...cantly axected by the level of segmentation, the pattern is not the same in each country and a decrease in segmentation can lead to either lower or higher volatility.

The remainder of this paper is organized as follows. Section 2 presents a simple model for the exects of trading restrictions on expected returns. Section 3 describes the data and presents some descriptive statistics. Section 4 presents regression results for the direct exect of market segmentation on expected returns. Section 5 presents empirical results allowing for time variation in country betas, Section 6 analyzes the volatility in the emerging markets, and Section 7 tests whether our results are robust by including control variables in the analysis. The ..nal section contains some concluding remarks.

\section{Expected returns and market integration}

The standard International CAPM (Adler and Dumas, 1983) assumes that markets are completely integrated: there are no investment barriers between countries and all agents can freely invest in all countries. In such a setting, the expected country returns depend on the covariance of those returns with the world market portfolio and possibly with currency deposits. If on the other hand a market is completely segmented, standard asset pricing models imply that the expected country return is proportional to the local return variance. If markets are partially segmented, some assets can be traded freely, which we refer to as the investable assets, whereas other assets can only be 
traded by domestic agents, which we refer to as the non-investable assets. In such a case the portfolio of investable assets may serve as a hedge for the non-investable assets, and therefore it may also enter the pricing equation (see, e.g., Errunza and Losq, 1985). We use a similar setting with timevarying levels of market segmentation to analyze the expected returns on the investable assets.

Suppose there are $\mathrm{K}$ markets available with excess dollar returns given by the vector $r_{t+1}$, the ith element of which is $r_{i ; t+1}$. For certain countries, like the emerging markets, foreign investors may not be able to freely trade all assets, and part of the assets must be held by local investors. The excess dollar returns on these noninvestable assets are denoted by the vector $r_{t+1}^{x}$, the ith element of which will be denoted by $r_{i ; t+1}^{x}$. For simplicity assume that there is only one (representative) mean-variance investor per country, with wealth equal to $Y_{t}^{i}$. Expected returns on the investable indices are given by the vector ${ }^{1} r$, whereas the expected returns for the noninvestables are given by ${ }^{1} x$. For a mean-variance investor in emerging market $j$, who can also invest in his own country's noninvestable assets, the ..rst order conditions are

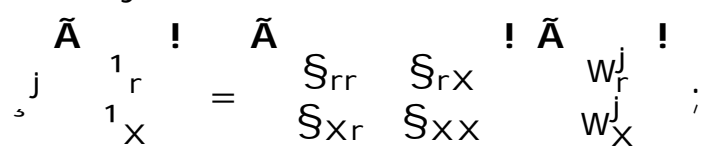

where ${ }^{j}$ is the inverse of the risk aversion of representative investor $j$. The

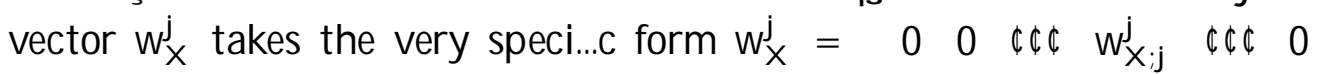
because only the local investor in country $j$ can invest in that country's noninvestable assets. An investor that lives in a country where all assets are investable, can only invest in $r_{t+1}$. We refer to such an investor as the world investor, whose ..rst order conditions are given by

$$
{ }^{1}{ }_{r}=\S_{r r} w_{r}:
$$

It is shown in the appendix that aggregating over all agents (countries), we get for the investable assets that

$$
E_{t}\left[r_{i ; t+1}\right]={ }^{\circ m} \operatorname{Cov}_{t} r_{i ; t+1}^{h} ; r_{t+1}^{w}{ }^{i}\left(1 ; \S_{j} q_{j ; t}^{m}\right)+{ }^{\circ m}{ }_{j=1}^{*} \operatorname{Cov}_{t} r_{i ; t+1}^{h} ; r_{j ; t+1}^{x} q_{j ; t}^{m}
$$

where ${ }^{\circ \mathrm{m}}$ is the global aggregated risk aversion, $r_{t+1}^{w}$ is the return on the world market portfolio of investable assets, and $q_{j ; t}^{m}$ is the nontraded asset position in country $j$ as a fraction of total invested wealth: 


$$
q_{j ; t}^{m}=\frac{P_{t}^{j} W_{X}^{j}}{k=1} Y_{t}^{k}=\frac{Q_{t}^{j}}{Y_{t}^{W}}
$$

The ..rst term in this equation is familiar from the standard World CAP M ; the second term is a discount on the risk premium if the asset provides a hedge against the risk of the non-investable asset returns. Since this relation must also hold for the expected return on the world market portfolio, we obtain a familiar beta-form of the model:

$$
\begin{aligned}
& E_{t}\left[r_{i ; t+1}\right]={ }^{-} E_{t}{ }_{t}^{h} r_{t+1}^{w}{ }^{i}+{ }_{j=1}^{*} \mu_{i j} q_{j ; t}^{m} ; \\
& -_{i}=\operatorname{Cov}{ }^{h} r_{i ; t+1} ; r_{t+1}^{w}{ }^{i}=\operatorname{ar}{ }^{h} r_{t+1}^{w} \text {, } \\
& \mu_{i j}=\circ{ }^{n} \operatorname{Cov}{ }^{h} r_{i ; t+1} ; r_{j ; t+1}^{x}{ }_{i}^{i}{ }_{i}{ }_{i} \operatorname{cov}{ }^{h} r_{t+1}^{w} ; r_{j ; t+1}^{x}{ }^{i o}
\end{aligned}
$$

where for notational convenience we leave out the time subscripts for the coec cients ${ }^{-}{ }_{i}$ and $\mu_{i j}$. This model is a natural generalization of the World CAPM where the additional terms are now the fractions of the nontraded assets in all countries in terms of total assets in the world. The presence of these terms cause extra risk premia because of the hedging demand by domestic agents for their position in the non-investable assets. Notice from equation (3) that if the local investable assets $r_{i ; t+1}$ and the noninvestable assets $r_{i ; t+1}^{x}$ have similar risk characteristics, i.e. if $\operatorname{Cov} r_{i ; t+1} ; r_{i ; t+1}^{x}=\operatorname{Var}\left[r_{i ; t+1}\right]$, we get that the expected return on local assets is indeed a weighted average of the covariance with the world portfolio and the local variance as in Bekaert and Harvey (1995), with time-varying weights proportional to $\mathrm{q}_{\mathrm{i} ; \mathrm{t}^{*}}{ }^{3}$ Essentially Bekaert and Harvey (1995) try to estimate the level of integration that we try to measure directly with the segmentation variable $\mathrm{q}_{i ; \mathrm{m}}^{\mathrm{m}}$.

The parameters of the segmentation variables, $\mu_{i j}$, depend on the covariance of the local, non-investable return with all the investable returns, corrected for their covariance with the world market return. This covariance will be big for assets from the same market j or from related markets, implying that we can expect $\mu_{\mathrm{ij}}$ to be nonzero for domestic assets and for assets from countries in the same region as market $j$, where the economic links

\footnotetext{
${ }^{3}$ Strictly spreaking, this is only true if $\mu_{i j}$ is zero for $i \epsilon j$.
} 
may be strong ${ }^{4}$. An important implication of the model in (5) is therefore that additional risk premia relative to a standard International CAPM may arise for two reasons: one, because that country itself may be segmented; two, because economically related countries are segmented, which induces a hedging demand for the neighboring countries' assets.

For the noninvestable assets we can obtain a similar pricing relation, as shown in the appendix. Aggregating the ..rst order conditions over all countries now implies

$$
E_{t}{ }^{h} r_{j ; t+1}^{x} i=B_{j} E_{t}\left[r_{t+1}\right]+{ }^{\prime} q_{j}^{j} ;
$$

where

$$
\begin{aligned}
B_{j} & =\operatorname{Cov} r_{j ; t+1}^{x} ; r_{t+1}{ }^{i} \operatorname{Var}\left[r_{t+1}\right]^{j 1} ; \\
{ }^{\prime} & =\circ{ }^{n} \operatorname{Var}\left[r_{x ; t+1}^{j}\right] B_{j} \operatorname{Cov}\left[r_{t+1} ; r_{j ; t+1}^{x}\right]^{o}
\end{aligned}
$$

and

$$
q_{t}^{j}=\frac{Y_{t}^{j} w_{X ; j}^{j}}{Y_{t}^{j}}=\frac{Q_{t}^{j}}{Y_{t}^{j}}:
$$

The segmentation variable is now a local variable, i.e., it rełects the market value of the noninvestable assets in country $j$ as a fraction of total investable wealth in that country rather than as a fraction of total investable wealth of the world. Notice that if the size of the segmented market relative to the rest of the world does not change too much over time, $q_{; ; t}^{m}$ is proportional to $q_{t}^{j}$. We will use this as a working assumption in the empirical analysis.

The second dixerence with the investable assets is that the expected return of the noninvestable assets does not depend on the covariance with the world portfolio, but on all the individual covariances of the noninvestables of country $\mathrm{j}$ with all the investable markets in the world: the coec cients $B_{j}$ result from regressing the noninvestable asset returns $r_{j ; t+1}^{x}$ on all the investable assets $r_{t+1}$ rather than on the world portfolio. The coed cient ' ${ }_{j}$ likewise depends on the residual " $t+1$ of this regression. Using

$$
r_{j ; t+1}^{x}=a_{j}+B_{j} r_{t+1}+{ }^{\prime \prime} t+1 ;
$$

\footnotetext{
${ }^{4}$ Notice that the model does not exclude the possibility that $\mu_{\mathrm{ij}}$ is negative. However, since $r_{j ; t+1}^{x}$ are the noninvestable assets from couptry $j$ which cannot be held by foreign investors, the covariance with the world index $\operatorname{Cov}^{2} r_{t+1}^{w} ; r_{j ; t+t_{1}}^{x}$ will typically be dominated by the covariance with the domestic investable assets, $\operatorname{Cov} r_{i ; t+1} ; r_{j ; t+1}^{x}$.
} 
we can write following equation (8b)

$$
{ }^{\prime}{ }_{j}={ }^{0}{ }_{j} \operatorname{Var}\left["{ }_{t+1}\right]
$$

which shows the familiar result that in segmented markets the local variance is priced, where the local risk aversion determines the market price of risk.

Hence, in case markets are segmented, the expected returns of both the investable and the noninvestable assets in these markets are axected by the level of segmentation in that market. Unlike the investable assets, the expected returns on the noninvestable assets is axected by the local segmentation variable only, and not by the level of segmentation in other countries.

\section{Data}

\subsection{Emerging market returns}

Our dataset consists of monthly US Dollar-based observations on 30 emerging markets, that are grouped into four regions: Latin A merica (7), A sia \& the Far East (10), Europe (7), and the Mideast \& A frica (6). In addition to the individual countries, we also use aggregate data for each of the four regions, and for a composite index of all emerging markets together. Depending on the country, the sample period is from J anuary 1988 or later until M ay 2000. All emerging markets data are from the E merging Markets DataB ase of the International Finance Corporation. In addition, the $\mathrm{MSCl}$ World index is used as a proxy for the world market index. These data are obtained from Datastream.

Table 1 presents summary statistics for the IF C Investable indices for the emerging markets. The ..rst two columns show the annualized means and standard deviations of the monthly dollar returns. These statistics illustrate some well known properties of emerging market returns: Many emerging markets have experienced high average returns, but at the same time most of these markets have been very volatile, as can be seen from the standard deviations of the returns. Also, there is a lot of cross-sectional variation in the returns, as can be seen from the mean returns which vary between $-35.1 \%$ for Slovakia and $50.0 \%$ for Argentina.

Table 2 shows the betas of the emerging markets with respect to the world market index, along with the associated t-statistics. The ..rst two columns show these statistics for the IFC Investable indices. Columns 5 
and 6 likewise present the statistics for the Global indices. The estimates for these two sets of indices are very similar. Most emerging markets have systematic risk estimates that are signi..cantly dixerent from zero, and often even signi..cantly bigger than one.

\subsection{Segmentation variables}

The main focus of this paper is the exect of market segmentation on expected returns. The third and fourth column of Table 1 give some insight into the relevance of investment barriers for the dixerent emerging markets. These columns present the means and standard deviations of our segmentation variable, which is based on the market value of the investable and noninvestable assets in each country. M ore precisely, let $V_{t}^{j}$ represent the value of the assets in country $j$ at time t which can be held by both domestic and foreign investors without restrictions. These are the investable assets and are measured by the total market capitalization of the IFC Investable Index for country $j$. Similarly, let $Q_{t}^{j}$ represent the value of the assets in country $\mathrm{j}$ at time $\mathrm{t}$ that can only be held by domestic investors. The total invested wealth in country $j$ is then given by $Y_{t}^{j}=V_{t}^{j}+Q_{t}^{j} T$ hese are the noninvestable assets, and are measured by the dixerence in the total market capitalization of the IFC Global Index and the IFC Investable Index for country $\mathrm{j}$. Our segmentation variable for country $\mathrm{j}$ is then de..ned as

$$
=\frac{Q_{t}^{j}}{V_{t}^{j}+Q_{t}^{j}}=\frac{Q_{t}^{j}}{Y_{t}^{j}} \text { : }
$$

Notice that the variables $Q_{t}^{j}$ and $V_{t}^{j}$ do not capture all the noninvestable and investable assets in a country, but only the assets that are included in the IFC indices. Also note that the model in Section 2 implies that this is the appropriate integration variable for the noninvestable assets, whereas for the investable assets, this is the ratio of $Q_{t}^{j}$ over ${ }_{j} Y_{t}^{j}$, i.e., the amount of noninvestable assets in country $j$ divided by the global aggregate wealth. As noted in Section 2, as long as the weight of country $j$ in the world portfolio is not too variable, these two segmentation variables will be proportional to each other, which we will use as a working assumption throughout the paper. An additional advantage of the variable is that it is always in the range $[0 ; 1]$ and that it has an easy interpretation: simply refects the percentage of assets in country $j$ that cannot be traded by foreign investors. 
As the third column of Table 1 shows, there is quite some variation be tween the average segmentation of the countries. Some markets, like Poland and South A frica, show hardly any segmentation: for those markets, on average more than 98 percent of the assets could be traded freely by both domestic and foreign investors. On the other hand, for countries like Chile, China, India, and K orea, on average more than 50 percent of the assets were not available for foreign investors, implying a high level of segmentation. The standard deviations of the segmentation variable show that many countries also have a signi..cant amount of variation in the level of segmentation over time. This con..rms the ..ndings of Bekaert and Harvey (1995) that the level of integration varies over time.

Several studies report liberalization dates for emerging markets, i.e., dates where a country's government allows foreign investors to purchase shares in that country's stock market (Henry, 2000, Bekaert and Harvey, 2000, and $\mathrm{Kim}$ and Singal, 2000). As Henry (2000, Table II) shows, there is no general agreement on the of cial liberalization date. Figure 1 shows how our segmentation variable relates to the o\$ cial liberalization dates (as reported by these dixerent authors in Henry, 2000) for a number of emerging markets. We only show graphs for those markets where liberalization dates are reported after the start of our dataseries, which leaves six countries. For three of the six countries in Figure 1, the ol cial liberalization dates are also obvious in our segmentation variable: For B razil, Colombia, and M exico, at least one of the reported dates coincides with a sharp decrease in the segmentation variable q. A though in those cases the liberalization clearly has an important exect on our segmentation variable, it is also obvious from the graphs that there is a lot of variation in that is not covered by the reported liberalization dates. Also, there are many liberalization dates reported in Henry (2000) that are not accompanied by a signi..cant change in $\$$. Thus, although an of cial liberalization can obviously cause a change in the level of segmentation, these two variables are clearly not equivalent. Since our segmentation variable captures much more than oф cial liberalizations only, we may be able to explain more of the variation in expected returns than Bekaert and Harvey (2000). The main point of this analysis is that liberalization is a gradual process, not a one-shot event. Our segementation measure allows for a simple and theoretically justi..ed way to assess the exect of liberalizations on expected returns. 


\section{Regression analysis}

The main question in this paper is whether the variability in translates into time varying expected returns, as suggested by the model in Section 2. We ..rst answer this question for the IFC Investable indices. The starting point of the analysis is Equation (5), which relates the expected returns on the investable assets to the level of segmentation in the dixerent countries. Assuming that all variances and covariances in (5) are constant over time, it is not hard to show that OLS estimation of the regression

$$
r_{i ; t+1}=\bigotimes_{1}+{ }^{-} r_{t+1}^{w}+{ }_{j=1}^{\mathcal{K}} \mu_{i j} j+{ }_{i ; t+1} ;
$$

yields consistent estimates of the coec cients ${ }^{-}{ }_{i}$ and $\mu_{i j}$.

\subsection{Segmentation exects from the own market on the investable indices}

We start out with a speci..cation where only $q$, i.e., the country's own integration variable, is included. Thus, here we estimate the regression

$$
r_{i ; t+1}=\mathbb{R}_{1}+{ }^{-}{ }_{i} r_{t+1}^{w}+\mu_{i} q^{i}+{ }^{i ; t+1} ;
$$

The ..rst four columns of Table 2 provide estimates of ${ }^{-}{ }_{i}$ and $\mu_{\mathrm{i}}$ along with the associated t-values ${ }^{5}$ where $r_{i ; t+1}$ is the return on the Investable index of market $\mathrm{i}$. The estimates show that for many markets the returns are signi..cantly axected by the level of integration. Especially for the Latin A merican markets, there are strong exects and the estimated coec cients $\beta_{i}$ are statistically signi..cantly dixerent from zero in ...ve out of seven countries. Notice that the estimated exects are not only statistically signi..cant, but also economically. For example, the estimated $\beta_{\mathrm{i}}$ of 0.61 for A rgentina implies that a one percentage point decrease in the level of segmentation as measured by q. would yield a decrease in the expected return of 0.61 percent, given the estimated $b_{i}$. For Asia and the Far East and for the European emerging markets, there is hardly any evidence of an exect of a country's level of segmentation on the expected returns in that same country.

\footnotetext{
${ }^{5} \mathrm{~A} / \mathrm{l}$ standard errors, t-statistics and Wald test-statistics reported in the paper are based on heteroskedasticity consistent estimates of the covariance matrix of the error terms in the dixerent regressions.
} 
Also, when looking at the regional indices, there is evidence in favor of an exect of segmentation on expected returns. These regional exects are in some contrast to the results for the individual countries, however. For Latin A merica and for the Mideast and A frica, the estimated $\mu_{\mathrm{i}}$ is not signi..cantly dixerent from zero, whereas for A sia and the Far East it is.

The results for the countries within each region are summarized in Table 3 , Panel A. The ..rst two columns show the average coeф cient $\mu_{\mathrm{i}}$ for countries within each region along with its standard error ${ }^{6}$. The third column provides the p-values associated with a Wald test-statistic for the hypothesis that $\mu_{i}=0$ in (12) for all countries within a region. These tests con..rm the ..nding that the level of segmentation is important for expected returns in Latin America and in the Mideast and Africa, but we do not ..nd such evidence for A sia and the Far East. The exects for the European countries are jointly signi..cant on a ten percent level, but not on the ..ve percent level. For the four regions, the joint hypothesis of no segmentation exects is rejected at the ten percent level, but not at the ..ve percent level. The integration exect is also signi..cant for the Composite index for all emerging markets. The averages for the dixerent regions show that the exect of market segmentation is rather diverse, ranging from 0.046 for A sia and the Far East to 0.528 for the mideast and Africa. The latter implies an exect of approximately 50 basis points per percentage change in the segmentation variable. For the Composite index we..nd an estimate $\beta_{\mathrm{i}}$ of 0.069 , implying that a decrease in the segmentation variable with one percent leads to a decrease in expected return of about seven basis points per month. This number can be interpreted as a value weighted average of all the emerging markets in our sample. These results are all economically very signi..cant.

In summary, these...rst results clearly indicate that the level of integration of an emerging market can have signi..cant exects on the expected returns in that market.

\footnotetext{
${ }^{6}$ T hus, for each region we report $\frac{1}{K}{ }_{i=1} P_{i} p_{i}$ and its cross sectional standard error. Notice though that this statistic merely gives an indication of the importance of segmentation in each region, since there is no reason why the $\mu$ 's in each country should be equal or even have the same sign.
} 


\subsection{R egional segmentation exects on the investable in- dices}

A part from a country's own level of segmentation, the model in Section 2 implies that there may also be cross exects on the investable assets from the level of segmentation of related markets, as can be seen from the de. nition of $\mu_{\mathrm{ij}}$ in (??). To the extent that markets $A$ and $B$ are correlated, segmentation in market $A$ may have an exect on the investable expected returns in market $B$ as well, because investable assets in market $B$ can serve as a (partial) substitute for the noninvestable assets in market $A$.

To see whether such cross exects are important, we use the integration variable for a given region $j$ such as $L$ atin A merica and estimate the regression in (12) for each country $i$ in that region. We then test the null-hypothesis that $\mu_{\mathrm{i}}=0$, for $\mathrm{i}=1 ; 2 ;: ; \mathrm{K}^{\mathrm{j}}$, for each region, where $\mathrm{K}^{\mathrm{j}}$ is the number of countries in region $j$. The fourth column of Panel A of Table 3 shows the $p$ values associated with the Wald test-statistics for this hypothesis. Although the evidence is somewhat weaker than for the country's own segmentation in the ..rst column, the regional segmentation is clearly important as well, at least for the Latin American countries and for the countries in the M ideast and Africa. For Asia and the Far East and for Europe there are no regional segmentation exects, but here the own country's segmentation also appears to be less relevant.

Looking at a more aggregate level, the last line of column 4 refers to a test whether the four regions are axected by the level of segmentation of all emerging markets, as represented by the Composite index. Although the four regions are obviously dixerent from each other and there are no strong economic linkages between them, the p-value of 0.046 suggests that they are all axected by the same global level of segmentation.

One problem with the use of the regional variable is that when regressing the return of country $i$ on the integration variable for region $j$, that region also includes country $i$ itself. Therefore, for each market i we construct an additional integration variable ${ }^{\text {ni }}$ that contains all markets in region $j$ except market $\mathrm{i}$. Thus, denoting the number of countries in region $\mathrm{j}$ as $\mathrm{K}^{\mathrm{j}}$, the integration variable is de..ned as

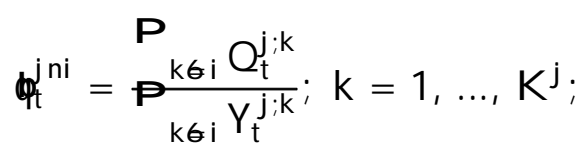

where the superscript $j ; k$ refers to country $k$ in region $j$. Using this variable, 
we estimate the regression

$$
r_{i ; t+1}=\mathbb{R}_{1}+{ }^{-}{ }_{i} r_{t+1}^{w}+\mu_{i} \phi t^{n i}+{ }^{n} i ; t+1 ;
$$

for each country in region $\mathrm{j}$ and test the hypothesis $\mathrm{H}_{0}: \mu_{\mathrm{i}}=0$, i $=$ $1 ; 2 ;:: ; \mathrm{K}^{\mathrm{j}}$. The p-values for a Wald-test of this hypothesis is reported in the last column of Table 3.

These p-values con..rm the importance of regional exects, beyond individual country exects. For the countries in Latin A merica and in A sia and the Far East the p-values in the last column are even lower than the ones in the fourth column of Panel A. Especially for A sia and the Far East, where we did not ...nd an exect from the country's own level of segmentation using the results in the ..rst column, this shows the importance of the region. The reverse seems to be true for the Mideast and A frica, where the segmentation level of the country itself is important, but the regional segmentation level is not. The average correlations between the countries in each region as reported in the last column of Panel $E$ of Table 1 con..rm this ..nding: whereas the average correlation between the countries in A sia and the Far East is 0.33 , for the countries in the Mideast and A frica it is only $0.12 .{ }^{7} \mathrm{No}$ tice that the average correlation between the four regions is as high as 0.57 , which explains why the cross regional exects have explanatory power at this aggregated level.

Summarizing, we ..nd that the level of integration is important in explaining expected returns in emerging markets. For Latin A merica, both the country's own level of integration as well as cross exects from countries in the same region are important. In A sia and the Far E ast, the regional exects appear to be more important than the individual country exects, whereas in the European emerging markets and the markets in the M ideast and A frica, the level of integration of the country itself is the most important. We also ..nd cross region exects between the four regions: the regional returns are not only axected by their own level of segmentation, but also by the global level and the level of segmentation in the other regions.

\footnotetext{
${ }^{7} \mathrm{~T}$ he correlation matrices for emerging markets can be obtained from the authors upon request.
} 


\subsection{R obustness: segmentation exects on the global in- dices}

The model in Section 2 suggests that both the investable and the noninvestable assets in a country are axected by the level of segmentation in a market. Equation (5) shows that the expected returns on the investable assets are determined by their covariance with the world market portfolio and by all relevant segmentation variables. On the other hand, according to Equation (7), the expected returns on the noninvestable assets are determined by the individual covariances of those assets with all other countries and by the local level of segmentation. If we make the simplifying assumption that as far as the investable assets are concerned the world market portfolio is still el cient for the investors in country i, even though there are nontraded assets, then Equation (7) simpli..es to

$$
E_{t}{ }^{h} r_{i ; t+1}^{x}{ }^{i}={ }^{-} E_{t}{ }_{t} r_{t+1}^{w}{ }^{i}+{ }^{\prime} q_{t} q^{i}:
$$

Therefore, the expected returns on the the noninvestable assets are also determined by the covariance with the world market portfolio and by the local segmentation variable. The dixerence between the noninvestable and the investable assets is that the expected returns on the latter are also axected by the level of segmentation in other countries because of cross hedging exects. Since for each country, the IFC Global indices, $r_{i ; t+1}^{G}$ are a combination of the investable indices $r_{i ; t+1}$ and the noninvestable indices $r_{i ; t+1}^{x}$, it follows that the expected global indices should also be arected by the covariance with the world market portfolio and the dixerent segmentation variables. However, because of the presence of the noninvestable assets in the IFC Global indices, relative to the IFC Investable indices they should be more sensitive to the local segmentation variables and less to the regional segmentation variables. Thus, in the regression

$$
r_{i ; t+1}^{G}=\bigotimes+{ }^{-}{ }_{i} r_{t+1}^{w}+\mu_{i} d+{ }^{i}{ }_{i ; t+1} ;
$$

we should ..nd relatively strong segmentation exects if $\mathrm{j}=\mathrm{i}$, and somewhat weaker exects if $\mathrm{j} G \mathrm{i}$.

Panel B of Table 3 shows the results for tests of the hypothesis $\mu_{\mathrm{i}}$ for dixerent choices of in (14). The ...rst column shows the test results for $\mathrm{j}=\mathrm{i}$, i.e., when the local segmentation variable is used. The p-values in the ..rst column of Panel B should be compared to the ones in the ..rst column of 
Panel A. The ..rst four $p$-values, which are based on the individual countries in the four regions are very similar to the ones in Panel $A$ and are indeed somewhat lower than in Panel A, except for the Mideast and Africa. The $p$-values for the regional indices and the Composite index are much higher in Panel B and show that for the G lobal indices there are no signi...cant segmentation exects from the own region or on a global level. This suggests that on a regional level, the noninvestable assets in a region like Latin A merica are not signi..cantly axected by the Latin A merican segmentation level. This is in fact consistent with our model, since the noninvestable assets should be axected by the segmentation of their own country rather than of the region. Thus, we..nd that for the IFC Global indices the local local market segmentation variables are more important than the regional variables, whereas for the Investable indices we found that the regional segmentation variables were important as well.

This pattern is con..rmed by the results in the second and the third column of Panel B. In the second column, we use the regional segmentation variable to explain the returns on the IFC Global returns of the individual countries and the world segmentation variable to explain the IFC G lobal returns of the four regions. These $p$-values can be compared with the corresponding $p$-values for the IFC Investable returns in the fourth column of Panel A. A gain we ..nd that the ..rst four $p$-values which are based on the individual countries in the four regions are similar in the two tables, but now we ..nd that except for the Mideast and A frica the p-values in Panel B are slightly higher than the corresponding ones in Panel $A$. This shows again that the regional segmentation exects on the Global indices are less significant than the exects on the Investable indices, as is implied by the model in Section 2. The third column of Panel B, which uses the regional segmentation variable ${ }^{\text {ni }}$ excluding the country itself and corresponds to the last column of $P$ anel $A$, further corroborates these ..ndings.

Therefore, we conclude that the local, and not the regional, segmentation variable is the most relevant factor in determining risk premia for the noninvestable assets.

\section{Time-varying covariances}

So far the analysis assumed that all covariances in the model in (5) and (7) are constant over time. This assumption may be problematic however, since 
as markets open up and become more integrated, their beta is expected to change as well. This is also shown in Bekaert and Harvey (2000), who ..nd an increase in the beta with the world portfolio of 0.12 following emerging markets liberalizations. Therefore, in this section we explicitly allow for time variation in beta as a result of changes in the level of segmentation. A ssuming that beta is linear in the segmentation variable, the model for the investable assets becomes

$$
E_{t}\left[r_{i ; t+1}\right]={ }^{3}-{ }_{0 i}+{ }^{-}{ }_{1 i} q_{t}^{j} E_{t}{ }^{h} r_{t+1}^{w}+\mu_{i} q_{t}^{j} ;
$$

where $q_{t}^{j}$ can be either a local or a regional segmentation variable. Thus, we estimate the following regression model:

$$
r_{i ; t+1}=\circledR_{1}+{ }^{3}{ }^{-}{ }_{0 i}+{ }^{-}{ }_{1 i} r_{t+1}^{w}+\mu_{i} \phi+{ }^{\prime}{ }_{i ; t+1}:
$$

We start by estimating (15) with the country's own segmentation variable as a dependent variable, i.e., $=$ for country i. Table 4 reports the estimates for ${ }^{-}{ }_{0 i},{ }_{1 i}$, and $\mu_{i}$ along with their t-values. The interesting coec cient is now ${ }^{-}{ }_{1 i}$. The estimated coec cients ${ }^{b}$ and their t-values clearly indicate time-variation for a number of countries. The estimates are signi..cantly different from zero for nine countries. Also, for the majority of the countries ${ }^{b}$ has the expected negative sign: as the level of segmentation decreases, markets become more integrated and their beta relative to the world increases. Allowing for time-varying betas makes the direct exects of segmentation on expected returns as measured by $\mu_{\mathrm{i}}$ somewhat stronger, as follows from the ...th and sixth column of Table 4 . The ..ndings here are comparable to the ones in Table 2, but the t-values are in general higher in Table 4.

Panel $E$ of Table 5 gives an estimate of the exect of market segmentation on the beta's and expected returns for the four regions and for all emerging markets together as represented in the Composite index. For the composite index we ..nd an estimate of ${ }^{-}{ }_{1}$ of -1.55 . This number means that if markets would change from completely segmented to not segmented ( $q^{\text {Comp }}$ would change form 1.0 to 0.0 ) then the beta of the composite index would increase by 1.55. During our sample period, ${ }^{\text {Comp }}$, the segmentation variable for the composite index changes by 5.5 percentage points per year, implying an annual increase in beta of the composite index of about 0.085. For the four regions the estimate for ${ }^{-}{ }_{1}$ varies between -0.62 for A sia and the Far East, and -3.18 for Latin A merica, although the ..rst estimate is not significantly dixerent from zero. These results are comparable with the ..ndings 
of B ekaert and Harvey (2000), who report changes in beta between 0.06 and 0.33 following liberalizations.

The change in beta due to a change in the segmentation variable is accompanied by a direct exect of market segmentation on the expected return as measured by $\mu_{\mathrm{i}}$. Allowing for time-variation in beta, the direct exect of market segmentation is now signi..cant for Latin A merica, A sia and the Far East, as well as for the composite index for all emerging markets. Also, except for Europe, ${ }^{-}{ }_{1 i}$ and $\mu_{\mathrm{i}}$ are al ways of the opposite sign, implying that a decrease in segmentation has two opposite exects on expected returns: the direct exect is negative, but the increase in beta has a positive exect. For the composite index, the estimate of ${ }^{-}$and $\mu$, combined with an annual change in $\boldsymbol{q}^{\text {Comp }}$ of 5.5 percentage points and an average return on the world portfolio of 1.04 percent per month (the sample average), we ..nd that the total exect of the decrease in market segmentation is 0:085 $f$ 0:0104 i 0:085 $f$ 0:055 $=$ i 0:0038. Thus, the annual decrease in expected returns on the composite emerging market index due to the average annual decrease in market segmentation is estimated to be 38 basis points per month or about 4.5 percent per year.

Similarly, the last two columns of Table 4 present estimates of the annual decrease in expected returns due to the average annual change in segmentation for all the emerging markets in our dataset, along with the standard errors of the estimates, where it is assumed that the expected return on the world market portfolio is $1.04 \%$ per month, or about $12.5 \%$ per year. Although for most markets these estimates are reasonable, they can be very big for some individual countries like I srael. However, the standard errors also show that the estimates for the individual countries are often very imprecise. For the composite index, we see that the estimate of $4.5 \%$ is fairly precise, with a standard error of 1.5\%. For Latin A merica and for A sia and the Far East we ..nd similar results as for the Composite index, but for Europe and the Mideast and A frica the estimates are less than 1.5 standard errors away from zero and here the estimates do not even have the expected sign.

Table 5 presents tests for the exects of market segmentation on the betas as well as the direct exects, for all regions. The table presents $p$-values associated with Wald test-statistics for the hypothesis that ${ }^{-}{ }_{1 i}=0$ and for the hypothesis that $\mu_{\mathrm{i}}=0$, for all countries within a region, as well as for all four regions and for the Composite index. Panel $A$ presents the results for the IFC Investable indices. The ..rst two columns test for the exect of a country's or region's own segmentation level. Except for the Mideast and A frica we can always reject the hypothesis of a constant beta. Also, controlling for the 
time-variation in beta, we ..nd strong evidence of a direct exect of the own segmentation level for all regions except Asia and the Far East. Both the direct exect and the exect on beta are also apparent for the regional indices and for the Composite index.

The next two columns look at the exect of the regional segmentation variables on the country returns and the country betas and on the exect of the global segmentation variable on the returns and betas of the regional indices. Again we ..nd strong segmentation exects, both direct and via the betas. Interestingly, for A sia and the Far E ast the regional exect appears to operate through the direct exect $\left(\mu_{\mathrm{i}}\right)$ and not through the exect on the betas. The opposite appears to be the case for the E uropean emerging markets. This is con..rmed in the last two columns, where similar to the results in Table 3 , we test for the exect of the regional segmentation, excluding the country itself. Thus, here we use the segmentation variable ${ }^{\text {ni }}$ as de..ned in (13) in the regression in (15). The cross segmentation exects for A sia and the Far East and for the Mideast and A frica operate via the direct exect, whereas for the European emerging markets, they appear to operate via the betas only. Thus, for every region both the country's own segmentation level as well as the regional segmentation level are important, albeit for dixerent regions the exects operate mainly via the beta or via the direct exect.

Panel B of Table 5 reports the same tests for the IFC Global indices. As outlined in the previous section, because of the presence of the noninvestable assets, we can expect that the Global indices should be more sensitive to the local segmentation variables and less to the regional segmentation variables. However, we do not ..nd such a clear pattern in this case. The results for the Global indices are very similar to the results for the Investable indices reported in Panel A of Table 5 and the exect of the local (regional) segmentation variables may be stronger (weaker) for the indirect exect, but weaker (stronger) for the direct exect or vice versa. Therefore, we conclude that both the investable and the noninvestable assets in a country are - directly or indirectly - axected by both the local and regional levels of segmentation.

\section{Time-varying volatility}

The above analysis showed strong direct and indirect exects from segmentation on the expected returns of a country. The indirect exects, operating via the beta of a country w.r.t. the world market portfolio, indicate that 
as a market becomes more integrated with the rest of the world, its systematic risk increases. Beakert and Harvey (2001) and Bae and Chan (2001) have similar results, and $B$ ae and $C$ han also ..nd that investable stocks have a higher volatility than noninvestable stocks. On the other hand, previous studies (e.g. Bekaert and Harvey (1997)) suggest that as markets liberalize, equity market volatility decreases. Therefore, we may expect that there is also a relation between the level of segmentation and local market volatility. In order to investigate this issue we propose to use a GARCH model for the idiosyncratic volatility in (15) and use the segmentation variable as an exogenous variable in the GARCH model. Speci..cally, we estimate the following model:

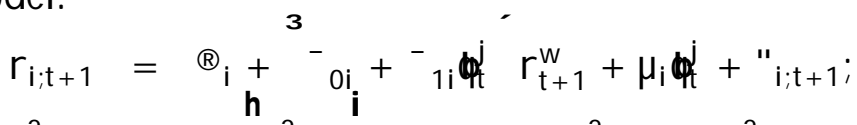

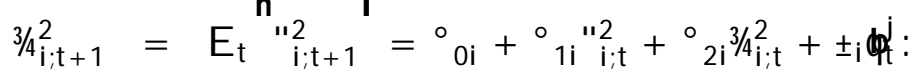

If segmentation indeed leads to higher volatility, we expect $\ddagger$ to be positive.

Table 6 shows the estimation results for the model in (16) where we use both the local $(\mathrm{j}=\mathrm{i})$ and the regional segmentation variables $\mathrm{f}$, and we investigate the exect of these variables on both the Investable and the Global IFC indices for the countries in our dataset. To save space we only report the estimates of \pm along with the associated p-values for the hypothesis that $t_{i}=0 .{ }^{8 ; 9}$ The ..rst four columns of Table 6 show the results for the IFC Investable indices. Here we see that for nine out of 30 individual countries, there is a signi..cant exect of the local segmentation variable on idiosyncratic volatility, at least at the ten percent level. However, the estimated coec cient can be both positive or negative, i.e., an increase in market integration can lead to both a decrease or an increase in the idiosyncratic risk of a country's stock market. The exects of the regional segmentation variables are somewhat similar: there are signi..cant exects for six individual countries, and the estimated coec cients are often negative, at least in the cases where they are signi..cantly dixerent from zero. For the Investable indices for the regions we do not ...nd any signi...cant results.

The last four columns of Table 6 present similar results for the IFC Global indices. Although the results for the individual countries and regions do not

\footnotetext{
${ }^{8} \mathrm{~T}$ he complete estimation results for the GARCH model can be obtained from the authors upon request.

${ }^{9}$ We also experimented with asymmetric GARCH models (cf. Bekaert and Harvey, 1997) but it turned out that the asymmetries were not very pronounced and did not axect the estimates of the segmentation exects. We therefore do not report these results.
} 
coincide for the Global and the Investable indices, the pattern is qualitatively the same. There are signi..cant exects from the local (regional) segmentation variables on ten (eight) individual countries, and these exects can be either positive or negative. For Europe and the Mideast and Africa, we now also ..nd signi...cant exects of the global segmentation variable on the regional indices.

Thus, the exects of the level of segmentation on the idiosyncratic risk of the emerging markets are rather inconclusive. Although there are exects from the level of segmentation on volatility, as witnessed both by the tests for the individual countries and the joint tests for the dixerent regions, the sign of the exect is not clear. An increase in the level of integration with the rest of the world may lead to either a decrease or an increase in the volatility of the market. Moreover, for a given country the exect of the local level of integration can even be opposite to exect of the regional level of integration, as is the case for instance for Sri Lanka. Thus, whereas we found clear evidence that more integrated markets lead to lower expected returns, such a conclusion cannot be reached for the volatility in emerging markets.

\section{Control variables}

The asset pricing model in Section 2 suggests that expected asset returns are related to a direct measure for the level of segmentation of a country's ..nancial markets. However, from previous studies it is well known that expected returns in emerging markets are axected by other variables as well. For instance, Erb, Harvey, and Viskanta (1995) show that dixerent country risk factors (political, economic, and ...nancial) contain information about expected equity returns. Such variables are likely to refect relevant risk factors that are not captured by the beta of the country with respect to the world market portfolio. Next, besides our direct measure of ..nancial segmentation, previous studies have also used other variables to measure integration or segmentation. For instance, Bekaert and Harvey (2000) and Carrieri, Errunza, and Hogan (2001) use a country's market capitalization relative to its GDP and the size of the trade sector (exports plus imports) relative to GDP as measures for economic integration. Such variables can capture elements of segmentation or integration beyond our direct measure.

In this section we want to analyze whether our direct segmentation variable contains information about expected stock returns that is not captured 
by other risk or integration variables. Therefore, we repeat our previous tests by including in the regression two additional variables, labelled country risk $\left(\right.$ crisk $_{t}$ ) and openness $\left(\right.$ open $\left._{t}\right)$. The country risk measure is the composite risk index from the International Country Risk Guide (ICRG). This measure is a simple function of the three base risk measures of the ICRG for political, economic, and ..nancial risk, and has been analyzed in detail by Erb, Harvey, and Viskanta (1995). The openness variable is the ratio of export and import over GDP, which is also used as a control variable by Bekaert and Harvey (2000). As stated, these two measures are supposed to capture a country's risk and level of integration respectively. For the four regions and for the Composite level, we create a weighted average of the country risk and openness variables respectively, where the weights are given by the country's market capitalization at the beginning of each month.

Table 7 shows some information as to how these variables are related to our (direct) segmentation variable, qt. The ..rst two columns of Table 7 then show the average absolute correlations of the two variables with our segmentation variables in a region or for all emerging markets together. B oth variables have a fairly high correlation with the level of segmentation $q_{t}$ for the individual countries and for the four regions. It is only for the Composite level itself that the correlations are relatively low. Especially the openness variable has a rather high average correlation with our segmentation variable, which is to be expected, since both try to measure a level of integration in a country. Finally, the last column shows the $\mathrm{R}^{2}$ of a regression of the segmentation variable $\mathrm{q}_{\mathrm{t}}$ on $\mathrm{crisk}_{\mathrm{t}}$ and open $_{\mathrm{t}}$.

We proceed our analysis with the following regression:

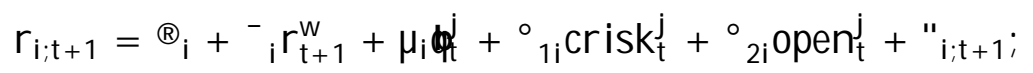

where $r_{i ; t+1}$ can be the return on either the Investable index or the Global index of market $i$ and is again the segmentation variable for market i itself, the region of market $i$, or the region excluding the market itself. The level of aggregation that is used for the control variables $\operatorname{crisk}_{t}^{j}$ and open ${ }_{t}^{j}$, is the same as for Panel A of Table 8 shows test results for the IFC Investable indices in dixerent regions and can be compared with $P$ anel $A$ of Table 3. The numbers in the table are p-values associated with a Wald-test for the hypothesis that $\mu_{\mathrm{i}}=0$ for all markets in a region and for the hypothesis that ${ }^{\circ}{ }_{1 i}={ }^{\circ}{ }_{2 i}=0$ for all markets in a region.

For the own level of segmentation, we see that the results in the ..rst column of $\mathrm{P}$ anel $\mathrm{A}$ are roughly comparable to the results in Table 3. The main 
dixerence is that in Table 3 we found segmentation exects that were significant at the ten percent level for Europe and for the four regions, whereas these exects are no longer signi...cant in Table 8. The second column of Table 8, which tests for the exects of the country's risk and its openness on the returns, shows that the control variables also have strong exects on the returns. However, as we found before, there is still information in our segmentation measure about expected returns beyond the information that is present in the control variables. The ..rst column of Panel B shows the results for the same tests for the Global indices, where the conclusions are the same as for the Investable indices: the results basically con..rm the ..ndings of Table 3.

The next columns of Table 8 present similar tests, but now for segmentation exects from the region and from the region excluding the market itself respectively. Here we see that the segmentation exects are now much less signi...cant than could be concluded from Table 3. It is only for Asia and the Far E ast that we ..nd signi...cant exects (unlike in Table 3). At the same time, we do ..nd that there is an exect of the country's risk and openness variables on the expected returns.

F inally, Table 9 reports tests for segmentation exects when the betas of the countries with respect to the world portfolio can be time-varying. Here, the tests are based on the regression:

$$
r_{i ; t}={ }+{ }^{3}{ }^{-}{ }_{0 i}+{ }^{-}{ }_{1 i} d^{\prime} r_{t+1}^{w}+\mu_{i}{ }^{j}+{ }^{o}{ }_{1 i} \operatorname{crisk} k_{t}^{j}+{ }^{\circ}{ }_{2 i} \operatorname{open}_{t}^{j}+{ }_{i ; t+1} \text { : }
$$

The table shows $p$-values for tests of direct segmentation exects $\mathrm{H}_{0}: \mu_{\mathrm{i}}=0$, indirect segmentation exects, $\mathrm{H}_{0}:{ }^{-}{ }_{1 i}=0$, and exects from the control variables, $\mathrm{H}_{0}:{ }^{0}{ }_{1 \mathrm{i}}={ }^{0}{ }_{2 \mathrm{i}}=0$. These results can be compared with Table 5 , which shows similar test results for the regression without the control variables.

For the direct segmentation exects $\left(\mu_{\mathrm{i}}\right)$ of the own market the results are similar as in case of constant beta's in Table 8: there are strong exects from the market's own level of segmentation, except for the four regions. For the regional level of segmentation we ..nd that, unlike the constant beta case, now there are strong direct exects for dixerent markets. These results can be both stronger or weaker than in case of no control variables. For the indirect exects $\left({ }_{i}\right)$, our results are very similar to the case of no control variables in Table 5 . The individual $p$-values can be both higher or lower in Table 8 relative to Table 5, but overall we ..nd that the indirect exect of our segmentation variable does not change materially. 
In summary we ..nd that the country's risk rating and its openness certainly contain information about expected returns that is not captured by our segmentation variable. But the level of segmentation has signi...cant direct and indirect exects on returns in emerging markets and these exects are not very dixerent whether we control for these additional variables or not.

\section{Summary and conclusions}

We use a simple model in which market integration or segmentation is a time-varying variable which has an exect on expected returns apart from systematic risk. Using a set of 30 emerging markets we ..nd strong evidence for the exects of the level of segmentation on the expected returns in emerging markets. Integration with the world market leads to lower expected returns and hence lower costs of capital. Expected returns in emerging markets are axected by the level of segmentation in the country itself, but also by the level of segmentation in other countries in the same region. Likewise, the expected returns in the four regions are axected by the level of segmentation in the region itself, but also by the global level of segmentation as measured by the Composite index for the emerging markets. Whereas the emerging markets in Europe and in the Mideast and A frica are mostly axected by the level of segmentation of the country itself, we ..nd that in Asia and the Far East the regional segmentation level is more important. For the Latin A merican countries both variables are important.

We also allow for time-variation in the country's and region's betas relative to the world. Allowing for betas that are linear in the segmentation variables shows even stronger segmentation exects on expected returns. The direct exect of segmentation and the exect on beta usually have the opposite sign: whereas the direct exect of a decrease in segmentation leads to lower expected returns, it is accompanied by an increase in beta, implying higher expected returns. As for the direct exects, the beta can be axected by the segmentation level of the country itself or of the regional segmentation level. For every region both the country's own segmentation level as well as the regional segmentation level are important, albeit for dixerent regions the exects operate mainly via the beta or via the direct exect. All these conclusions are robust to controls for the country risk rating and openness as measured by imports and exports over GDP.

As the model predicts, for the noninvestable indices we ..nd that the local 
level of segmentation or integration is more important than the regional level. This is a natural ..nding, since the noninvestable assets in a country cannot serve as a hedge for foreign investors for the noninvestable assets in other countries. However, this ..nding is most apparant when we focus on the direct exect of segmentation only, but is less clear when also allow for the indirect exect via time-varying betas.

Finally, although our model only relates to expected returns, we also analyze the relation between segmentation and volatility in emerging markets. Here we do not ..nd any systematic relation: although we do ..nd that the level of segmentation is often signi..cantly related to volatility, our GARCHspeci..cation shows that a decrease in segmentation can lead to either an increase or decrease in idiosyncratic risk in an emerging market. 


\section{R eferences}

2 Adler, M ichael, and Bernard Dumas, 1983, International portfolio selection and corporate ..nance: A synthesis, J ournal of F inance 46, 925984.

2 B ae, Kee-Hong, and K alok Chan, 2001, Investability and R eturn Volatility in E merging E quity M arkets, Working Paper, Hong K ong U niversity of Science and Technology.

2 Bekaert, Geert, and Campbell R. Harvey, 1995, Time-varying world market integration, J ournal of Finance 50, 403-444.

2 Bekaert, Geert, and Campbell R. Harvey, 1997, Emerging Equity Market Volatility, J ournal of F inancial Economics, 43, 29-77.

2 Bekaert, Geert, and Campbell R. Harvey, 2000, Foreign speculators and emerging equity markets, J ournal of Finance 55, 565-614.

2 Carrieri, Francesca, V ihang Errunca, and K ed Hogan, 2001, Characterizing World Market Integration through Time, Working Paper, McGill University.

2 De Roon, Frans A., Theo E. Nijman, and Chris Veld, 2000, Hedging pressure exects in futures markets, J ournal of Finance 55, 1437-1456.

2 Erb, Claude B., Campbell R. Harvey, and Tadas E. Viskanta, 1995, "Political Risk, Economic Risk, and Financial Risk", Financial Analysts J ournal, November/ December 1995, p.29-46.

2 Errunza, Vihang, and Etienne Losq, 1985, International asset pricing under mild segmentation: Theory and test, J ournal of Finance 40, 105-124.

2 Errunza, Vihang, Etienne L osq, and Prasad Padmanabhan, 1992, Tests of integration, mild segmentation, and segmentation hypotheses, J ournal of Banking and Finance 16, 949-972.

2 Errunza, Vihang R., and Darius P. M iller, 2000, Market segmentation and the cost of capital in international equity markets, Working Paper, Texas A\&M University. 
2 Henry, Peter Blair, 2000, Stock market liberalization, economic reform, and emerging market equity prices, J ournal of Finance 55, 529-564.

2 Hirshleifer, David, 1988, Residual risk, trading costs, and commodity futures risk premia, Review of Financial Studies 1, 173-193.

2 K im, E. Han, and Vijay Singal, 2000, Stock market openings: Experience of emerging economies, J ournal of Business 73, 25-66.

2 Mayers, David, 1976, N onmarketable assets, market segmentation, and the level of asset prices, J ournal of F inancial and Quantitative A nalysis 11, 1-12.

2 Stulz, René, 1999, International portfolio łows and security markets, Working Paper, Dice Center for F inancial E conomics, Ohio State University. 


\section{A A ppendix: Derivation of the model}

As in Section 2, let there be $K$ countries with excess returns on the investable indices $r_{t+1}$, where some countries, the emerging markets, also have noninvestable indices which cannot be traded by foreign investors. The returns on the non-investable indices are summarized in the vector of excess dollar returns $r_{x ; t+1} A$ world investor is restricted to investing in the $\mathrm{K}$ investable indices, implying that his ..rst order conditions look like

$$
{ }^{j{ }_{1}}{ }_{r}=\S_{r r} W_{r}^{j} ;
$$

with ${ }^{j}=1=^{\mathrm{j}}$, i.e., the inverse of the local risk aversion.

$M$ arket segmentation is modelled by limiting the menu of available assets for some investors, while every investor chooses the optimal portfolio from the available assets. For an emerging market investor, who can also invest in his own market $j$, the ..rst order conditions are

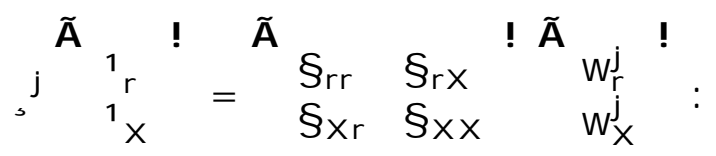

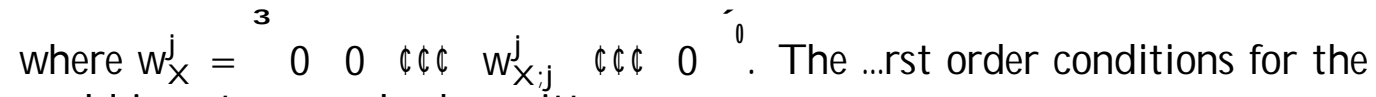
world investor can also be written as

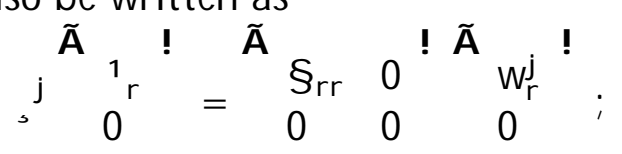

which has the advantage that for every investor we have matrices with the same dimensions.

The next step is to aggregate over all investors, who have relative wealth $y^{j}=Y^{j}=Y^{W}$, where $Y^{j}$ is the wealth of investor $j$ and $Y^{W}$ is total world wealth. Now de..ne

$$
{ }_{j} y^{j}, j={ }^{m}=1=0 m ;
$$

and impose the equilibrium conditions

$$
\begin{aligned}
& { }^{x} y^{j} w_{x}^{j}=q^{m} ; \\
& \dot{x}^{j} w_{r}^{j}=w\left(1 ; \quad q^{w}\right) ;
\end{aligned}
$$


where $q^{m}$ are the 'hedging pressures' with elements $q^{m}=Q^{j}=Y w, w$ are the weights (in terms of the total value of investible assets) of the world portfolio of investable indices, and $q^{w}=j q^{m}$ is the fraction of total wealth locked into noninvestible assets. Aggregating the .rst order conditions therefore gives

$$
,{ }_{r}^{m_{1}}=\left(1 ; \quad q^{w}\right) \S_{r r} w+\S_{r x} q^{m} ;
$$

for the vector of investable indices and

$$
{ }^{j 1}{ }_{x}=\S \times r w_{r}^{j}+\S x \times q^{j} ;
$$

for each of the noninvestable indices.

\section{A.1 Expected return-beta relation for the investable indices}

For the investable indices, we get

$$
\begin{aligned}
1_{r} & =\left(1 ; q^{w}\right)^{\circ m_{\S} r w^{m}}+{ }^{\circ m_{\S}} r_{r \times} q^{m}, \\
1_{r} ; \circ m_{\S} r q^{m} & =\left(1 ; q^{w}\right)^{\circ m_{\S} r m}:
\end{aligned}
$$

Premultiplying with $w^{0}$ gives

$$
\begin{aligned}
& { }^{1}{ }_{w} i^{\circ m} \S_{w x} q^{m}=\left(1 ; q^{w}\right)^{\circ m_{3} / m_{m}}, \\
& \circ m=\left(1 ; q^{w}\right)^{i 1_{3} / \phi_{m}^{2} f^{1}{ }_{w} i^{\circ m_{\S}} w \times q^{m} g ;}
\end{aligned}
$$

which, after substituing in the previous relation gives

$$
\begin{aligned}
1_{r} & ={ }^{1}{ }_{w}+f q^{m} ; \\
E_{t}\left[r_{i ; t+1}\right] & ={ }_{j} E_{t}\left[r_{t+1}^{w}\right]+\S_{j} \mu_{i j} q_{i t}^{m} ; \\
{ }_{i} & =\operatorname{Cov}\left[r_{i, t+1} ; r_{t+1}^{w}\right]=V \operatorname{ar}\left[r_{t+1}^{w}\right] ; \\
\mu_{i j} & ={ }^{w}{ }^{n} \operatorname{Cov}\left[r_{i ; t+1} ; r_{j ; t+1}^{x}\right]{ }^{x}{ }_{i} \operatorname{Cov}\left[r_{t+1}^{w} ; r_{j ; t+1}^{x}\right]^{\circ}:
\end{aligned}
$$

\section{A.2 Expected return-beta relation for the noninvestable indices}

For the expected returns on the noninvestable index in a country, we can start from (19). The ..rst order conditions for the tradable assets give us

$$
w_{r}^{j}=\S_{r r}^{i 1}{ }^{n},{ }^{j}{ }_{r} i \S_{r X ; j} w_{X}^{j}{ }^{o} ;
$$


which after substitution in the ..rst order conditions for the nontraded assets in market $\mathrm{j}$ gives

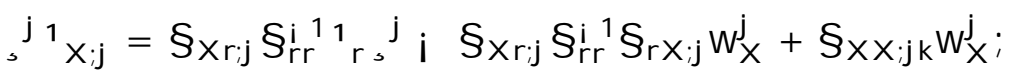

from which

$$
\begin{aligned}
& { }^{1} X_{j ;}=B_{j}{ }^{1}{ }_{r}+{ }^{1}{ }_{j} w_{X}^{j} ; \\
& E_{t}\left[r_{j ; t+1}^{X}\right]=B_{j} E_{t}\left[r_{t+1}\right]+{ }^{x}{ }_{j} q_{t}^{j} ; \\
& B_{j}=\operatorname{Cov}\left[r_{j ; t+1}^{x} ; r_{t+1}\right] \operatorname{Var}\left[r_{t+1}\right]^{i}{ }^{1} ; \\
& { }_{j}={ }^{\prime} j^{n} \operatorname{Var}\left[r_{j ; t+1}^{x}\right]_{i} \operatorname{Cov}\left[r_{j ; t+1}^{x} ; r_{t+1}\right] \operatorname{Var}\left[r_{t+1}\right]^{11} \operatorname{Cov}\left[r_{t+1} ; r_{j ; t+1}^{x}\right]^{0}
\end{aligned}
$$

Thus, the $B_{j}$ are the slope coet cients from a regression of $r_{j: t+1}^{X}$ on all the investable assets, and ' $j$ depends on the variance of the residuals from the same regression and the local risk aversion. Thus, in the regression

$$
r_{j ; t+1}^{x}=a_{j}+B_{j} r_{t+1}+{ }_{t+1} ;
$$

we should have that ${ }^{\prime}{ }_{j}=0 j 3 / 4$. Also notice that $q_{t}^{j}$ is de. ned in terms of local wealth, not in terms of global wealth as $q_{t}^{m}$. 
Table 1: Summary Statistics

The table gives summary statistics for returns and the fraction noninvestable assets in a country or region. Means and standard deviations of returns are annualized and in percentages. The last column of Panel $\mathrm{E}$ reports for each region the average correlation between the country returns within each region, excluding the correlation of each country with itself. For the row "Comp" this is the average correlation between the four region, excluding the correlation of each region with itself. All data are based on monthly dollar-based observations in the period J anuary 1988 until M ay 2000.

\begin{tabular}{|c|c|c|c|c|}
\hline \multicolumn{5}{|c|}{ Panel A: Latin America } \\
\hline & \multicolumn{2}{|c|}{ returns } & \multicolumn{2}{|c|}{ segmentation } \\
\hline & mean $(\%)$ & v (\%) & mean $(\%)$ & stdev (\%) \\
\hline Arg & 50.0 & 82.8 & 5.0 & 6.3 \\
\hline Bra & 40.3 & 69.1 & 38.0 & 25.6 \\
\hline Chi & 24.0 & 27.2 & 50.6 & 37.9 \\
\hline Col & 20.0 & 38.2 & 22.0 & 10.4 \\
\hline Mex & 25.9 & 35.6 & 17.9 & 21.6 \\
\hline Per & 11.3 & 32.2 & 9.5 & 5.0 \\
\hline Ven & 38.1 & 61.7 & 29.6 & 23.4 \\
\hline \multicolumn{5}{|c|}{ Panel B: Asia \& Far E ast } \\
\hline & \multicolumn{2}{|c|}{ returns } & \multicolumn{2}{|c|}{ segmentation } \\
\hline & mean $(\%)$ & $v(\%)$ & mean (\%) & stdev (\%) \\
\hline Cin & 3.3 & 47.1 & 86.1 & 8.8 \\
\hline Ind & 6.4 & 30.1 & 76.0 & 2.9 \\
\hline Ido & 0.1 & 53.0 & 40.4 & 23.4 \\
\hline Kor & 9.9 & 49.0 & 66.2 & 33.5 \\
\hline Mal & 12.6 & 38.9 & 17.8 & 9.3 \\
\hline Pak & 15.9 & 44.2 & 40.1 & 25.9 \\
\hline Phi & 6.6 & 39.6 & 52.8 & 3.7 \\
\hline Sri & -4.9 & 35.0 & 63.0 & 11.3 \\
\hline Tai & 14.9 & 36.2 & 79.1 & 18.6 \\
\hline Tha & 6.7 & 43.7 & 65.8 & 9.1 \\
\hline
\end{tabular}




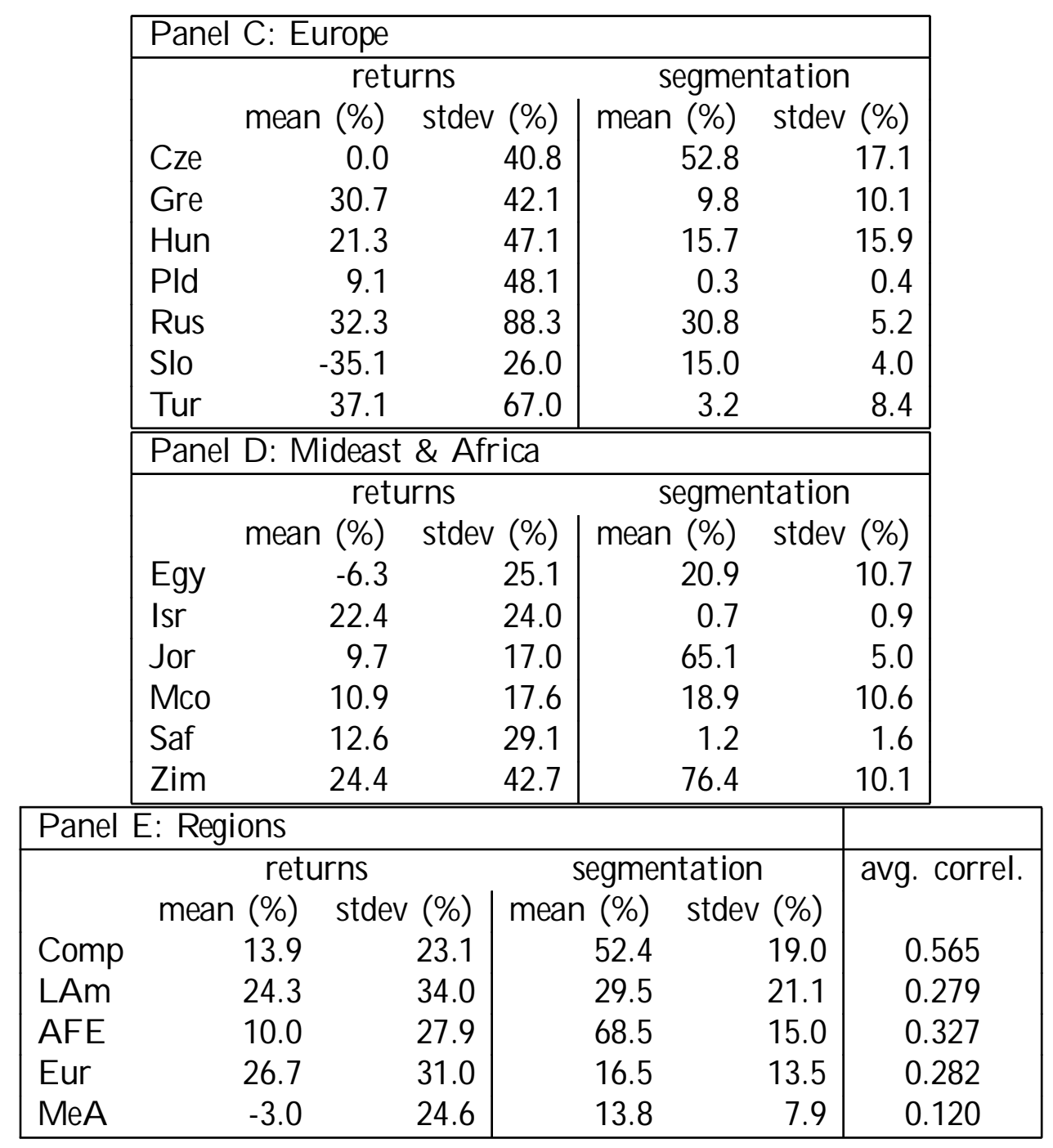


Table 2: Systematic risk and segmentation exects for individual countries and regions

The coet cients in the table are based on the regression

$$
r_{i ; t+1}=\mathbb{B}_{1}+{ }^{-}{ }_{i} r_{t+1}^{w}+\mu_{i} q_{t}^{i}+{ }^{1 ;} ; t+1 ;
$$

where is the segmentation level of market i. The ..rst four columns are for the IFC Investable indices, the last four for the IFC Global indices. Heteroskedasticity consistent t-values are in parantheses. All data are based on monthly dollar-based observations in the period J anuary 1988 until M ay 2000.

\begin{tabular}{|c|c|c|c|c|c|c|c|c|}
\hline \multicolumn{9}{|c|}{ anel A: Latin America } \\
\hline & & $|\mathrm{FC}|$ & vestable & & & IFC & Şobal & \\
\hline & & $t\left(^{-}\right)$ & $\mu$ & $t(\mu)$ & & $\mathrm{t}\left(^{-}\right)$ & $\mu$ & $t(\mu)$ \\
\hline Arg & 0.74 & (1.54) & 0.610 & (1.86) & 0.72 & (1.53) & 0.540 & (1.68) \\
\hline Bra & 1.55 & (3.75) & 0.101 & $(1.08)$ & 1.44 & (3.87) & 0.069 & $(0.89)$ \\
\hline Chi & 0.64 & (3.02) & 0.046 & (2.79) & 0.60 & (2.84) & 0.043 & (2.64) \\
\hline Col & 0.34 & $(0.97)$ & 0.363 & $(2.87)$ & 0.25 & $(0.76)$ & 0.352 & (2.69) \\
\hline Mex & 1.35 & (7.31) & 0.082 & (2.19) & 1.29 & (6.76) & 0.046 & (1.40) \\
\hline Per & 0.92 & (2.78) & 0.172 & $(0.68)$ & 0.88 & $(2.72)$ & 0.173 & $(0.71)$ \\
\hline Ven & 0.01 & $(0.01)$ & 0.137 & (1.89) & 0.06 & $(0.12)$ & 0.099 & (1.64) \\
\hline Pane & $\overline{B: A s}$ & ia \& F & East & & & & & \\
\hline & & $|F C|$ & ivestable & & & & Global & \\
\hline & - & $\mathrm{t}\left(^{-}\right.$ & $\mu$ & $t(\mu)$ & & $\mathrm{t}\left(^{-}\right)$ & $\mu$ & $t(\mu$ \\
\hline Cin & 1.03 & (2.76) & -0.207 & (1.22) & 0.19 & $(0.61)$ & -0.249 & (1.57) \\
\hline Ind & 0.28 & (1.04) & 0.117 & $(0.35)$ & 0.28 & (1.12) & 0.041 & $(0.12)$ \\
\hline Ido & 1.90 & $(4.6$ & 0.010 & & 1.84 & $(4.70)$ & 0.002 & 10.0 \\
\hline Kor & 1.31 & $(4.24)$ & -0.080 & $(2.00)$ & 1.33 & (4.35) & -0.080 & (2.02) \\
\hline Mal & 1.23 & (5.1 & 0.147 & (1.35) & 1.21 & (5.12) & 0.139 & (1.30) \\
\hline Pak & 0.34 & & 0.082 & & 0.38 & $(1.00)$ & 0.073 & (1.63) \\
\hline Phi & 1.33 & & 0.204 & & 1.34 & $(4.90)$ & -0.002 & $(0.01)$ \\
\hline Sri & 0.83 & & 0.118 & & 0.59 & $(2.08)$ & 0.106 & (1.39) \\
\hline Tai & 1.11 & $(4.2$ & 0.002 & $(0.03)$ & 1.12 & $(4.31)$ & 0.004 & $(0.07)$ \\
\hline Tha & 1.54 & (6.56) & 0.072 & $(0.55)$ & 1.58 & (6.44) & 0.064 & $(0.47)$ \\
\hline
\end{tabular}




\begin{tabular}{|c|c|c|c|c|c|c|c|c|}
\hline \multicolumn{9}{|c|}{ Panel C: E urope } \\
\hline & \multicolumn{4}{|c|}{ IFC Investable } & \multicolumn{4}{|c|}{ IFC G lobal } \\
\hline & & $\mathrm{t}\left(^{-}\right)$ & $\mu$ & $t(\mu)$ & & $\mathrm{t}\left(^{-}\right)$ & $\mu$ & $t(\mu)$ \\
\hline Cze & 0.97 & (2.26) & -0.060 & $(0.83)$ & 0.58 & (1.64) & -0.063 & (1.05) \\
\hline Gre & 0.55 & (1.99) & 0.076 & $(0.69)$ & 0.54 & (2.04) & 0.039 & $(0.39)$ \\
\hline Hun & 1.87 & $(4.83)$ & 0.023 & $(0.21)$ & 1.75 & $(5.07)$ & 0.004 & $(0.04)$ \\
\hline PId & 1.65 & (3.97) & 3.075 & $(0.77)$ & 1.65 & (3.97) & 3.070 & $(0.76)$ \\
\hline Rus & 3.64 & (6.91) & -1.511 & (2.69) & 3.37 & (5.68) & -1.667 & (2.95) \\
\hline Slo & -0.17 & $(0.85)$ & 0.411 & (1.56) & -0.19 & (1.07) & 0.284 & (1.18) \\
\hline Tur & 0.45 & $(0.93)$ & 0.479 & (1.37) & 0.49 & (1.05) & 0.511 & (1.63) \\
\hline \multicolumn{9}{|c|}{ Panel D: Mideast \& Africa } \\
\hline & \multicolumn{4}{|c|}{ IFC Investable } & \multicolumn{4}{|c|}{ IFC Global } \\
\hline & - & $\mathrm{t}\left(^{-}\right)$ & $\mu$ & $t(\mu)$ & & $t\left(^{-}\right)$ & $\mu$ & $t(\mu)$ \\
\hline Egy & 0.42 & (1.61) & -0.073 & $(0.67)$ & 0.37 & (1.45) & -0.086 & $(0.81)$ \\
\hline Isr & 0.64 & (3.11) & 1.508 & (3.68) & 0.64 & (3.10) & -1.176 & $(0.21)$ \\
\hline J or & 0.25 & (2.02) & 0.158 & (2.27) & 0.23 & (2.00) & 0.107 & (1.65) \\
\hline M co & -0.33 & (2.24) & 0.102 & (1.20) & -0.29 & (1.98) & 0.106 & (1.20) \\
\hline Saf & 1.17 & (4.23) & 1.085 & (2.32) & 1.28 & (4.67) & 1.050 & (2.18) \\
\hline Zim & 0.91 & (2.14) & 0.385 & (2.73) & 0.94 & (2.38) & 0.398 & $(2.87)$ \\
\hline \multicolumn{9}{|c|}{ Panel E: Regions } \\
\hline & \multicolumn{4}{|c|}{ IFC Investable } & \multicolumn{4}{|c|}{ IFC Global } \\
\hline & & $\mathrm{t}\left({ }^{-}\right)$ & $\mu$ & $t(\mu)$ & & $t\left(^{-}\right)$ & $\mu$ & $\mathrm{t}(\mu)$ \\
\hline Comp & 1.08 & (7.70) & 0.069 & (2.51) & 0.97 & (6.24) & 0.036 & (1.24) \\
\hline LAm & 1.13 & (4.81) & 0.086 & (1.48) & 1.10 & (5.40) & 0.058 & (1.22) \\
\hline AFE & 1.19 & (7.68) & 0.075 & (2.12) & 0.92 & $(5.52)$ & 0.029 & $(0.72)$ \\
\hline Eur & 1.16 & (3.47) & -0.047 & $(0.60)$ & 1.22 & (3.65) & -0.010 & $(0.13)$ \\
\hline MeA & 1.04 & (5.24) & 0.125 & (1.29) & 0.94 & (4.91) & 0.120 & (1.33) \\
\hline
\end{tabular}


Table 3: Segmentation exects from the own market and the region The table reports test results for the presence of segmentation exects on expected returns in emerging markets, The tests are based on the regression

$$
r_{i ; t+1}=\Theta_{1}+{ }^{-}{ }_{i} r_{t+1}^{w}+\mu_{i} \phi t+{ }_{i ; t+1} ;
$$

where is the segmentation level of the market itseł, the region, or of the region excluding the market itself. The columns of the table reports $p$-values for a Wald test for the hypothesis that $\mu_{\mathrm{i}}=0$ for all markets in certain region. In Panel A $r_{i ; t+1}$ referes to the IFC Investable indices, whereas in Panel $B$ it refers to the IFC Global indices. All data are monthly dollar-based observations in the period J anuary 1988 until May 2000.

\begin{tabular}{|c|c|c|c|c|c|}
\hline & \multicolumn{3}{|c|}{ Own segmentation } & \multirow{2}{*}{$\begin{array}{c}\text { Regional segmentation } \\
\qquad H_{0}: \mu=0\end{array}$} & \multirow{2}{*}{$\begin{array}{c}\text { Excl. own country } \\
H_{0}: \mu=0\end{array}$} \\
\hline & $\operatorname{avg}\left(\beta_{\mathrm{i}}\right)$ & $\mathrm{s}: \mathrm{e}:\left(\beta_{\mathrm{i}}\right)$ & $H_{0}: \mu=0$ & & \\
\hline LAm & 0.216 & $(0.066)$ & 0.001 & 0.005 & 0.004 \\
\hline AFE & 0.046 & $(0.057)$ & 0.329 & 0.119 & 0.049 \\
\hline Eur & 0.356 & $(0.568)$ & 0.079 & 0.844 & 0.620 \\
\hline $\mathrm{MeA}$ & 0.528 & (0.113) & 0.000 & 0.030 & 0.106 \\
\hline Reg & 0.060 & $(0.036)$ & 0.077 & 0.046 & 0.055 \\
\hline Comp & 0.069 & $(0.027)$ & 0.011 & & \\
\hline \multicolumn{6}{|c|}{ Panel B: IFC Global indices } \\
\hline & \multicolumn{3}{|c|}{ Own segmentation } & Regional segmentation & Excl. own country \\
\hline & & & $H_{0}: \mu=0$ & $\mathrm{H}_{0}: \mu=0$ & $H_{0}: \mu=0$ \\
\hline LAm & & & 0.007 & 0.029 & 0.076 \\
\hline AFE & & & 0.228 & 0.121 & 0.171 \\
\hline Eur & & & 0.048 & 0.871 & 0.702 \\
\hline $\mathrm{MeA}$ & & & 0.001 & 0.015 & 0.017 \\
\hline Reg & & & 0.438 & 0.223 & 0.162 \\
\hline Comp & & & 0.211 & & \\
\hline
\end{tabular}


Table 4: Regression results with time-varying beta's

The table gives regression results for segmentation exects when the beta of a country can be time-varying. The coec cients ${ }^{-}{ }_{0},{ }_{1}$; ; and $\mu$ are the OLS estimates from the regression

$$
r_{i ; t+1}=\Theta_{1}+{ }^{3}-{ }_{0 i}+{ }^{-}{ }_{1 i} \phi^{j} r_{t+1}^{w}+\mu_{i} \phi+{ }_{i ; t+1} ;
$$

where $q_{t}^{i}$ is the segmentation level of country $i$. $t$-values are in parentheses. The column change gives the decrease in the annual expected return due to the average annual change in the segmentation variable, as a percentage. s.e.(change) gives the standard error of the estimated decrease. All data are monthly dollar-based observations in the period J anuary 1988 until May 2000.

\begin{tabular}{|c|c|c|c|c|c|c|c|c|}
\hline \multicolumn{9}{|c|}{ Panel A: Latin America } \\
\hline & & $\mathrm{t}\left({ }^{-} 0\right)$ & & $\mathrm{t}\left({ }^{-}{ }_{1}\right)$ & $\mu$ & $t(\mu)$ & change(\%) & s:e:(change) \\
\hline Arg & 1.55 & (2.21) & -13.42 & (1.73) & 0.691 & (2.11) & 8.54 & (5.04) \\
\hline Bra & 2.29 & (3.16) & -1.75 & (1.27) & 0.115 & (1.77) & 7.37 & $(4.88)$ \\
\hline Chi & 1.07 & $(4.29)$ & -0.94 & (2.29) & 0.057 & (3.30) & 3.88 & (1.36) \\
\hline Col & 0.79 & $(0.96)$ & -2.00 & $(0.58)$ & 0.382 & (3.72) & 10.32 & (2.77) \\
\hline Mex & 1.72 & (6.82) & -2.36 & (2.23) & 0.124 & (3.17) & 9.22 & (3.26) \\
\hline Per & 0.30 & (0.62) & 7.03 & (1.50) & 0.116 & $(0.57)$ & 7.08 & (7.45) \\
\hline Ven & 1.28 & (1.97) & -4.15 & (2.49) & 0.182 & (2.60) & 9.19 & (4.47) \\
\hline \multicolumn{9}{|c|}{ Panel B: Asia \& Far East } \\
\hline & & $\mathrm{t}\left({ }^{-}{ }_{0}\right)$ & & $\mathrm{t}\left({ }^{-}{ }_{1}\right)$ & $\mu$ & $t(\mu)$ & change(\%) & s:e:(change) \\
\hline Cin & 2.32 & $(0.67)$ & -1.4 & $(0.37)$ & -0.185 & (1.07) & -8.72 & $(7.23)$ \\
\hline Ind & 6.05 & $(0.90)$ & -7.72 & $(0.86)$ & 0.230 & (0.67) & 1.37 & (2.93) \\
\hline Ido & 2.87 & $(5.02)$ & $-2.9 !$ & (2.16) & 0.052 & $(0.89)$ & 1.53 & (3.99) \\
\hline Kor & 2.49 & $(4.06)$ & -2.3 & (2.40) & -0.055 & (1.37) & -9.98 & $(4.90)$ \\
\hline Mal & 1.88 & $(4.07)$ & -4.2 & (1.61) & 0.207 & (2.05) & 4.23 & (2.45) \\
\hline Pak & 0.75 & (1.26) & -1.2 & $(0.84)$ & 0.092 & (1.87) & 5.43 & (3.29) \\
\hline Phi & 8.33 & $(2.53)$ & -13.2 & (2.13) & 0.415 & (1.62) & -0.71 & $(0.61)$ \\
\hline Sri & -1.30 & $(0.42)$ & 3.2 & $(0.69)$ & 0.053 & $(0.39)$ & -0.86 & (1.07) \\
\hline Tai & 0.90 & $(0.88)$ & 0.2 & $(0.21)$ & -0.001 & $(0.02)$ & 0.12 & (3.36) \\
\hline Tha & 5.39 & (3.25) & -6.0 & $(2.35)$ & 0.155 & $(1.40)$ & 2.58 & (2.92) \\
\hline
\end{tabular}




\begin{tabular}{|c|c|c|c|c|c|c|c|c|}
\hline \multicolumn{9}{|c|}{ Panel C: E urope } \\
\hline & & $\mathrm{t}\left({ }^{-}{ }_{0}\right)$ & & $t\left({ }^{-}{ }_{1}\right)$ & $\mu$ & $t(\mu)$ & change $(\%)$ & s:e:(change) \\
\hline Cze & -0.90 & $(0.81)$ & 3.48 & (1.76) & -0.104 & (1.31) & -5.49 & (6.09) \\
\hline Gre & 0.84 & (2.41) & -3.89 & (1.31) & 0.137 & (1.22) & 3.80 & (4.07) \\
\hline Hun & 1.39 & (3.15) & 4.79 & (1.85) & -0.027 & $(0.30)$ & 1.60 & (5.92) \\
\hline PId & 1.79 & (4.18) & -122.85 & $(0.77)$ & 5.452 & (1.17) & -0.56 & $(0.50)$ \\
\hline Rus & 11.00 & (2.68) & -24.38 & (1.82) & -1.102 & $(1.83)$ & -43.65 & (18.21) \\
\hline Slo & 0.61 & $(0.56)$ & -5.17 & $(0.73)$ & 0.499 & (1.50) & 24.16 & (17.06) \\
\hline Tur & 0.91 & (2.02) & -21.33 & (2.86) & 0.713 & (3.35) & 17.52 & (6.99) \\
\hline \multicolumn{9}{|c|}{ Panel D: Mideast \& Africa } \\
\hline & & $\mathrm{t}\left({ }^{-}{ }_{0}^{0}\right)$ & & $\mathrm{t}\left({ }^{-}{ }_{1}\right)$ & $\mu$ & $t(\mu)$ & change(\%) & s:e:(change) \\
\hline Egy & 1.06 & (1.81) & -2.95 & (1.21) & -0.029 & $(0.25)$ & -7.28 & $(13.48)$ \\
\hline & 0.16 & $(0.21)$ & 91.28 & $(0.69)$ & -1.954 & $(0.38)$ & -20.59 & (78.09) \\
\hline J or & 0.38 & (0.29) & -0.22 & (0.11) & 0.161 & (1.86) & 1.68 & $(0.88)$ \\
\hline Mco & -0.07 & $(0.20)$ & -1.38 & (0.87) & 0.121 & (1.53) & 12.38 & (8.85) \\
\hline Saf & 1.19 & (4.75) & -1.96 & $(0.13)$ & 1.096 & (2.26) & 5.08 & (2.28) \\
\hline Zim & 4.66 & $(2.04)$ & -5.25 & (1.66) & 0.438 & (3.40) & 11.03 & (3.59) \\
\hline \multicolumn{9}{|c|}{ Panel E: Regions } \\
\hline & & $\mathrm{t}\left({ }^{-}{ }_{0}\right)$ & & $\mathrm{t}\left({ }^{-}{ }_{1}\right)$ & $\mu$ & $t(\mu)$ & change(\%) & s:e:(change) \\
\hline Comp & 1.89 & (6.41) & -1.55 & (2.97) & 0.085 & (3.61) & 4.49 & $(1.50)$ \\
\hline LA m & 2.07 & (6.71) & -3.18 & (3.80) & 0.128 & (3.58) & 7.69 & (2.76) \\
\hline$A F E$ & 1.61 & (2.56) & -0.62 & $(0.69)$ & 0.080 & (2.05) & 4.05 & (2.10) \\
\hline Eur & 1.50 & (3.85) & -1.98 & (1.16) & -0.021 & $(0.26)$ & -0.43 & $(0.82)$ \\
\hline MeA & 1.37 & (3.37) & -2.43 & $(0.92)$ & 0.164 & (1.50) & -7.81 & (5.75) \\
\hline
\end{tabular}


Table 5: Tests for segmentation exects with time-varying beta's The table reports test results for the presence of segmentation exects on expected returns in emerging markets, The tests are based on the regression

$$
r_{i ; t+1}=\mathbb{B}_{1}+{ }^{-}{ }_{0 i} r_{t+1}^{w}+{ }^{-}{ }_{1 i} \phi r_{t+1}^{w}+\mu_{i} \phi d+{ }_{i j t+1 ;}
$$

where is the integration level of the market itself, the region, or of the region excluding the market itself. The columns of the table reports $p$-values for a Wald test for the hypothesis that ${ }^{-}{ }_{1 \mathrm{i}}=0$ or $\mu_{\mathrm{i}}=0$ for all markets in certain region. In Panel A $r_{i ; t+1}$ referes to the IFC Investable indices, whereas in Panel B it refers to the IFC Global indices. All data are monthly dollar-based observations in the period J anuary 1988 until May 2000.

\begin{tabular}{|c|c|c|c|c|c|c|}
\hline \multicolumn{7}{|c|}{ Panel A: IFC Investable indices } \\
\hline & \multicolumn{2}{|c|}{ Own segmentation } & \multicolumn{2}{|c|}{ Regional segmentation } & \multicolumn{2}{|c|}{ Excl. own country } \\
\hline & $\mathrm{H}_{0}:^{-}{ }_{1}=0$ & $H_{0}: \mu=0$ & $\mathrm{H}_{0}:{ }^{-}{ }_{1}=0$ & $H_{0}: \mu=0$ & $\mathrm{H}_{0}:^{-}{ }_{1}=0$ & $H_{0}: \mu=0$ \\
\hline LAm & 0.000 & 0.000 & 0.000 & 0.000 & 0.000 & 0.000 \\
\hline AFE & 0.014 & 0.263 & 0.474 & 0.065 & 0.172 & 0.027 \\
\hline Eur & 0.000 & 0.005 & 0.007 & 0.884 & 0.030 & 0.569 \\
\hline $\mathrm{MeA}$ & 0.294 & 0.000 & 0.029 & 0.002 & 0.493 & 0.022 \\
\hline Reg & 0.043 & 0.007 & 0.029 & 0.007 & 0.155 & 0.011 \\
\hline Comp & 0.002 & 0.001 & & & & \\
\hline \multicolumn{7}{|c|}{ Panel B: IFC Global indices } \\
\hline & \multicolumn{2}{|c|}{ Own segmentation } & \multicolumn{2}{|c|}{ Regional segmentation } & \multicolumn{2}{|c|}{ Excl. own country } \\
\hline & $\mathrm{H}_{0}:^{-}{ }_{1}=0$ & $H_{0}: \mu=0$ & $\mathrm{H}_{0}:^{-}{ }_{1}=0$ & $H_{0}: \mu=0$ & $\mathrm{H}_{0}:^{-}{ }_{1}=0$ & $H_{0}: \mu=0$ \\
\hline LAm & 0.001 & 0.000 & 0.000 & 0.000 & 0.000 & 0.000 \\
\hline AFE & 0.035 & 0.243 & 0.443 & 0.071 & 0.102 & 0.078 \\
\hline Eur & 0.000 & 0.007 & 0.009 & 0.866 & 0.085 & 0.392 \\
\hline MeA & 0.284 & 0.001 & 0.066 & 0.000 & 0.121 & 0.003 \\
\hline Reg & 0.039 & 0.094 & 0.039 & 0.075 & 0.107 & 0.057 \\
\hline Comp & 0.053 & 0.090 & & & & \\
\hline
\end{tabular}


Table 6: Estimates for time-varying volatility

The table gives regression results for segmentation exects on volatility

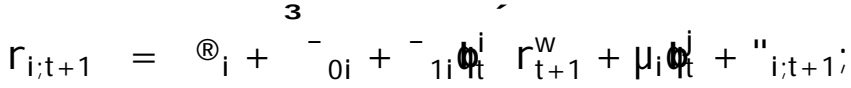

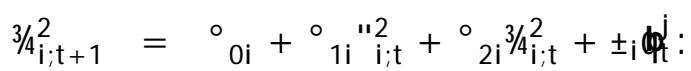

where $q_{t}^{j}$ is the segmentation level of country $i$ or of the region. The table shows the estimates for $\pm f 100$. p-values are in parentheses. The .rst four columns show the results for the IFC Investable indices, the last four columns for the IFC G lobal indices. The row "joint" shows the $p$-value associate with a Wald test statistic for the hypothesis that all coed cients $\ddagger$ are equal to zero.

\begin{tabular}{|c|c|c|c|c|c|c|c|c|}
\hline \multicolumn{9}{|c|}{ Panel A: Latin America } \\
\hline & \multicolumn{4}{|c|}{ IFC Investable indices } & \multicolumn{4}{|c|}{ IFC Global Indices } \\
\hline & \multicolumn{2}{|c|}{ local фi } & \multicolumn{2}{|c|}{ regional of } & \multicolumn{2}{|c|}{ local de } & \multicolumn{2}{|c|}{ regional of } \\
\hline & \pm & $p$ & \pm & $p$ & \pm & $p$ & & $p$ \\
\hline Arg & -0.35 & $(0.101)$ & -0.12 & $(0.001)$ & -0.54 & $(0.020)$ & -0.20 & $(0.002)$ \\
\hline Bra & -0.28 & $(0.001)$ & -0.34 & $(0.000)$ & -0.27 & $(0.002)$ & -0.32 & $(0.000)$ \\
\hline Chi & 0.32 & $(0.151)$ & 0.13 & $(0.320)$ & 0.28 & $(0.180)$ & 0.06 & $(0.377)$ \\
\hline Col & 0.52 & $(0.235)$ & -0.03 & $(0.482)$ & 0.44 & $(0.235)$ & -0.55 & (0.118) \\
\hline Mex & 0.03 & $(0.468)$ & 0.02 & $(0.475)$ & -0.19 & $(0.330)$ & -0.24 & $(0.278)$ \\
\hline Per & 0.46 & $(0.062)$ & 0.40 & $(0.233)$ & 0.86 & $(0.337)$ & 0.24 & $(0.294)$ \\
\hline Ven & 0.13 & $(0.244)$ & 0.28 & $(0.134)$ & -0.14 & $(0.054)$ & -0.43 & $(0.302)$ \\
\hline J oint (p-value) & & 000) & & 008) & & .001) & & $000)$ \\
\hline \multicolumn{9}{|c|}{ Panel B: Asia \& Far East } \\
\hline & \multicolumn{4}{|c|}{ IFC Investable indices } & \multicolumn{4}{|c|}{ IFC Global indices } \\
\hline & \multicolumn{2}{|c|}{ local \& } & \multicolumn{2}{|c|}{ regional of } & \multicolumn{2}{|c|}{ local фi } & \multicolumn{2}{|c|}{ regional of } \\
\hline & \pm & $p$ & \pm & $p$ & \pm & $p$ & \pm & $p$ \\
\hline Cin & -0.63 & $(0.399)$ & -1.12 & $(0.120)$ & 0.95 & $(0.325)$ & 1.91 & $(0.197)$ \\
\hline Ind & 0.87 & $(0.196)$ & 0.03 & $(0.316)$ & -0.02 & $(0.210)$ & 0.29 & $(0.391)$ \\
\hline Ido & -0.30 & (0.417) & -0.14 & $(0.407)$ & -0.31 & (0.482) & -0.08 & $(0.276)$ \\
\hline Kor & -1.73 & $(0.061)$ & -0.02 & $(0.493)$ & -1.99 & $(0.046)$ & 0.02 & $(0.475)$ \\
\hline Mal & -0.13 & $(0.245)$ & -0.11 & $(0.198)$ & -0.24 & $(0.103)$ & -0.14 & $(0.152)$ \\
\hline Pak & -0.94 & $(0.070)$ & -1.92 & $(0.136)$ & -0.20 & $(0.190)$ & -0.86 & $(0.058)$ \\
\hline Phi & 0.74 & $(0.443)$ & 0.32 & $(0.369)$ & -1.32 & $(0.300)$ & 0.00 & $(0.496)$ \\
\hline Sri & 0.41 & $(0.025)$ & -0.74 & $(0.000)$ & 0.27 & $(0.026)$ & -0.62 & $(0.000)$ \\
\hline Tai & 0.05 & $(0.154)$ & 0.10 & (0.158) & 0.04 & $(0.174)$ & 0.08 & $(0.145)$ \\
\hline Tha & 0.00 & $(0.500)$ & -0.22 & $(0.207)$ & -0.39 & $(0.291)$ & -0.25 & $(0.190)$ \\
\hline J oint (p-value) & \multicolumn{2}{|c|}{$(0.114)$} & \multicolumn{2}{|c|}{$(0.023)$} & \multicolumn{2}{|c|}{$(0.004)$} & \multicolumn{2}{|c|}{$(0.029)$} \\
\hline
\end{tabular}




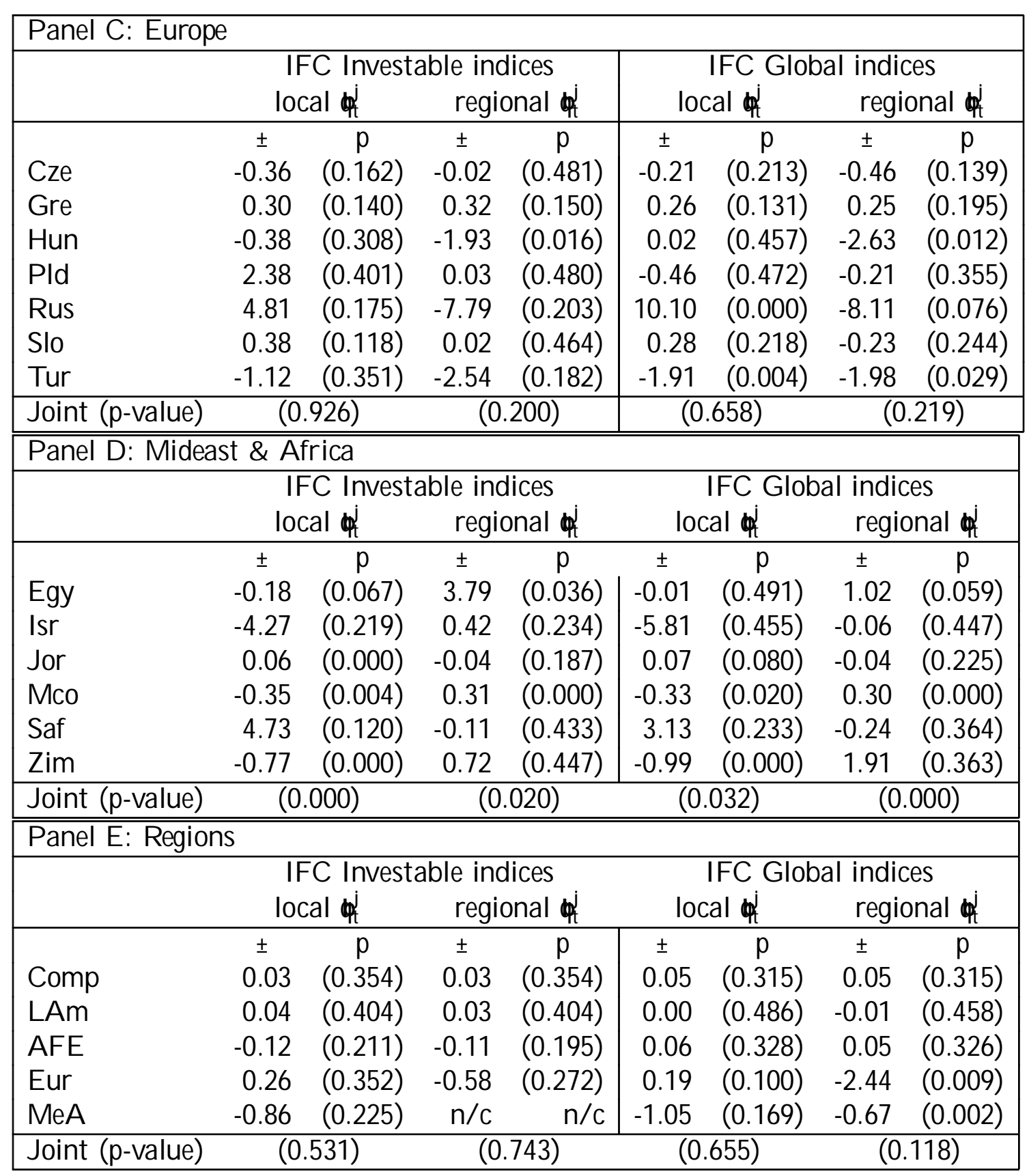


Table 7: Segmentation and control variables

The ..rst two columns of the table report the average absolute correlation of the segmentation variables of the countries and regions with the risk ratings and openness variables of theses countries and regions. The last column presents the average $\mathrm{R}^{2}$ 's from a regression of the segmentation variable on the risk rating and the openness.

\begin{tabular}{lccr}
\hline & corr(crisk, segm) & corr(open, segm) & $\mathrm{R}^{2}$ \\
\hline LAm & 0.533 & 0.538 & 0.471 \\
A FE & 0.394 & 0.681 & 0.621 \\
Eur & 0.494 & 0.586 & 0.502 \\
M eA & 0.346 & 0.461 & 0.422 \\
R eg & 0.394 & 0.709 & 0.582 \\
Comp & 0.057 & 0.327 & 0.135 \\
\hline
\end{tabular}


Table 8: Tests for segmentation exects with constant beta's and control variables

The table reports test results for the presence of segmentation exects on expected returns in emerging markets, with control variables for the country's risk rating (crisk) and the country's openness (open). The tests are based on the regression

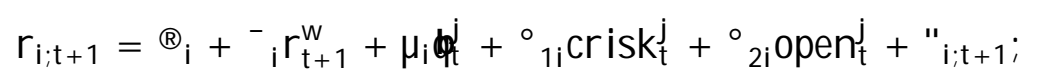

where is the integration level of the country, the region, or of the region excluding the country itself and crisk $k_{t}^{j}$ and open $n_{t}^{j}$ refer to the risk rating and openness of the country (..rst two columns) or the region (last four columns). The columns of the table reports $p$-values for a Wald test for the hypothesis that ${ }^{-}{ }_{1 i}=0$ or $\mu_{i}=0$ for all markets in certain region and for the hypothesis that ${ }^{\circ} \mathrm{ki}=0, \mathrm{k}=1 ; 2$. In Panel A $r_{i ; t+1}$ referes to the IFC Investable indices, whereas in Panel B it refers to the IFC Global indices. All data are monthly dollar-based observations in the period J anuary 1988 until May 2000.

\begin{tabular}{|c|c|c|c|c|c|c|}
\hline \multicolumn{7}{|c|}{ Panel A: IFC Investable indices } \\
\hline & \multicolumn{2}{|c|}{ Own segmentation } & \multicolumn{2}{|c|}{ Regional segmentation } & \multicolumn{2}{|c|}{ Excl. own country } \\
\hline & $H_{0}: \mu=0$ & $\mathrm{H}_{0}:{ }^{\circ}{ }_{k}=0$ & $\mathrm{H}_{0}: \mu=0$ & $\mathrm{H}_{0}:{ }^{\circ} \mathrm{k}=0$ & $H_{0}: \mu=0$ & $\mathrm{H}_{0}:{ }^{\circ} \mathrm{k}=0$ \\
\hline LAm & 0.014 & 0.000 & 0.535 & 0.071 & 0.877 & 0.037 \\
\hline AFE & 0.149 & 0.000 & 0.045 & 0.080 & 0.059 & 0.068 \\
\hline Eur & 0.145 & 0.629 & 0.346 & 0.044 & 0.243 & 0.455 \\
\hline MeA & 0.000 & 0.000 & 0.143 & 0.049 & 0.857 & 0.000 \\
\hline Reg & 0.367 & 0.240 & 0.105 & 0.292 & 0.150 & 0.345 \\
\hline Comp & 0.011 & 0.573 & & & & \\
\hline \multicolumn{7}{|c|}{ Panel B: IFC Global indices } \\
\hline & \multicolumn{2}{|c|}{ Own segmentation } & \multicolumn{2}{|c|}{ Regional segmentation } & \multicolumn{2}{|c|}{ Excl. own country } \\
\hline & $\mathrm{H}_{0}: \mu=0$ & $\mathrm{H}_{0}:{ }^{\circ} \mathrm{k}=0$ & $\mathrm{H}_{0}: \mu=0$ & $\mathrm{H}_{0}:{ }^{\circ}{ }_{k}=0$ & $\mathrm{H}_{0}: \mu=0$ & $\mathrm{H}_{0}:{ }^{\circ}{ }_{k}=0$ \\
\hline LAm & 0.008 & 0.000 & 0.465 & 0.012 & 0.693 & 0.014 \\
\hline AFE & 0.238 & 0.000 & 0.054 & 0.016 & 0.306 & 0.084 \\
\hline Eur & 0.107 & 0.556 & 0.687 & 0.050 & 0.388 & 0.412 \\
\hline MeA & 0.015 & 0.000 & 0.181 & 0.118 & 0.545 & 0.000 \\
\hline Reg & 0.337 & 0.041 & 0.478 & 0.444 & 0.508 & 0.438 \\
\hline Comp & 0.345 & 0.853 & & & & \\
\hline
\end{tabular}


Table 9: Tests for segmentation exects with time-varying beta's and control variables

The table reports test results for the presence of segmentation exects on expected returns in emerging markets, with control variables for the country's risk rating (crisk) and the country's openness (open). The tests are based on the regression

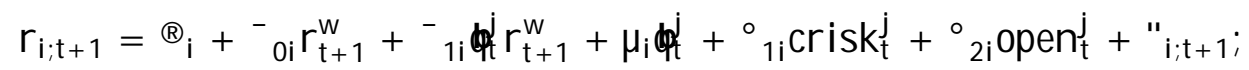

where is the integration level of the country, the region, or of the region excluding the country itself and crisk $\mathrm{t}_{\mathrm{j}}^{\mathrm{j}}$ and open $\mathrm{t}_{\mathrm{j}}^{\mathrm{j}}$ refer to the crisk rating and openness of the country (..rst two columns) or the region (last four columns). The columns of the table reports $p$-values for a Wald test for the hypothesis that $\mu_{\mathrm{i}}=0$ for all markets in certain region and for the hypothesis that ${ }^{\circ} \mathrm{ki}=0, \mathrm{k}=1 ; 2$. In Panel $A r_{i ; t+1}$ referes to the IFC Investable indices, whereas in Panel $B$ it refers to the IFC Global indices. All data are monthly dollar-based observations in the period J anuary 1988 until May 2000.

\begin{tabular}{|c|c|c|c|c|c|c|c|c|c|}
\hline \multicolumn{10}{|c|}{ Panel A : IFC Investable indices } \\
\hline & \multicolumn{3}{|c|}{ Own segmentation } & \multicolumn{3}{|c|}{ R egional segmentation } & \multicolumn{3}{|c|}{ Excl. own country } \\
\hline $\mathrm{H}_{0}:$ & ${ }_{1}=0$ & $\mu=0$ & ${ }^{\circ}{ }_{k}=0$ & ${ }_{1}=0$ & $\mu=0$ & ${ }^{\circ}{ }_{k}=0$ & ${ }_{1}=0$ & $\mu=0$ & ${ }_{\mathrm{r}}=0$ \\
\hline LAm & 0.000 & 0.004 & 0.000 & 0.000 & 0.098 & 0.107 & 0.000 & 0.275 & 0.077 \\
\hline AFE & 0.005 & 0.049 & 0.000 & 0.287 & 0.048 & 0.069 & 0.114 & 0.068 & 0.047 \\
\hline Eur & 0.000 & 0.019 & 0.521 & 0.031 & 0.481 & 0.044 & 0.077 & 0.420 & 0.569 \\
\hline $\mathrm{MeA}$ & 0.289 & 0.010 & 0.000 & 0.009 & 0.041 & 0.003 & 0.746 & & 0.002 \\
\hline Reg & 0.060 & 0.347 & 0.205 & 0.031 & 0.018 & 0.163 & 0.154 & 0.031 & 0.296 \\
\hline Comp & 0.003 & 0.001 & 0.617 & & & & & & \\
\hline \multicolumn{10}{|c|}{ Panel B: IFC Global indices } \\
\hline & \multicolumn{3}{|c|}{ Own segmentation } & \multicolumn{3}{|c|}{ Regional segmentation } & \multicolumn{3}{|c|}{ Excl. own country } \\
\hline $\mathrm{H}_{0}:$ & ${ }_{1}=0$ & $\mu=0$ & ${ }^{\circ}{ }_{k}=0$ & ${ }_{1}=0$ & $\mu=0$ & ${ }^{\circ}{ }_{k}=0$ & ${ }_{1}=0$ & $\mu=0$ & ${ }_{\mathrm{r}}{ }_{\mathrm{k}}=0$ \\
\hline LAm & 0.000 & 0.010 & 0.000 & 0.000 & 0.149 & 0.010 & 0.000 & 0.171 & 0.012 \\
\hline AFE & 0.016 & 0.089 & 0.000 & 0.028 & 0.043 & 0.008 & 0.063 & 0.283 & 0.057 \\
\hline Eur & 0.002 & 0.014 & 0.477 & 0.016 & 0.765 & 0.046 & 0.153 & 0.282 & 0.433 \\
\hline MeA & 0.250 & 0.010 & 0.000 & 0.010 & 0.015 & 0.004 & 0.136 & 0.473 & 0.002 \\
\hline Reg & 0.051 & 0.397 & 0.020 & 0.019 & 0.184 & 0.296 & 0.105 & 0.233 & 0.423 \\
\hline Comp & 0.046 & 0.192 & 0.724 & & & & & & \\
\hline
\end{tabular}


Figure 1: The ..gures show the segmentation variable used in this paper, along with the o $\$$ cial liberalization dates as reported by Bekaert and Harvey (2000), Henry (2000), and Kim and Singal (2000) and summarized by Henry (2000). 